San Jose State University

SJSU ScholarWorks

Master's Theses

Master's Theses and Graduate Research

Summer 2021

\title{
Analysis of Multi Resonant Switched Capacitive Converter with Imbedded PCB Elements
}

Adel Lahham

San Jose State University

Follow this and additional works at: https://scholarworks.sjsu.edu/etd_theses

\section{Recommended Citation}

Lahham, Adel, "Analysis of Multi Resonant Switched Capacitive Converter with Imbedded PCB Elements" (2021). Master's Theses. 5205.

DOI: https://doi.org/10.31979/etd.6quk-u7cu

https://scholarworks.sjsu.edu/etd_theses/5205

This Thesis is brought to you for free and open access by the Master's Theses and Graduate Research at SJSU ScholarWorks. It has been accepted for inclusion in Master's Theses by an authorized administrator of SJSU ScholarWorks. For more information, please contact scholarworks@sjsu.edu. 


\title{
ANALYSIS OF MULTI RESONANT SWITCHED CAPACITIVE CONVERTER WITH IMBEDDED PCB ELEMENTS
}

\author{
A Thesis \\ Presented to \\ The Faculty of the Department of Electrical Engineering \\ San José State University \\ In Partial Fulfillment \\ of the Requirements for the Degree \\ Master of Science \\ by \\ Adel Lahham
}

August 2021 
(C) 2021

Adel Lahham

ALL RIGHTS RESERVED 
The Designated Thesis Committee Approves the Thesis Titled

\section{ANALYSIS OF MULTI RESONANT SWITCHED CAPACITIVE CONVERTER WITH IMBEDDED PCB ELEMENTS}

by

Adel Lahham

APPROVED FOR THE DEPARTMENT OF ELECTRICAL ENGINEERING

SAN JOSÉ STATE UNIVERSITY

August 2021

Mohamad Badawy, Ph.D.

Ping Hsu, Ph.D.

Hiu Yung Wong, Ph.D.
Department of Electrical Engineering

Department of Electrical Engineering

Department of Electrical Engineering 


\section{ABSTRACT \\ ANALYSIS OF MULTI RESONANT SWITCHED CAPACITIVE CONVERTER WITH IMBEDDED PCB ELEMENTS}

by Adel Lahham

The data center industry is headed towards a lower point of load voltages with increased load demands contributing to higher $I^{2} R$ losses in power busses. Raising the bus voltage from $12 \mathrm{~V}$ to $48 \mathrm{~V}$ is a popular area investigated today for reducing power delivery losses. Switched capacitive converters (SCCs) are a popular topology used for this purpose. However, SCCs suffer from low tolerance for operating conditions and are unregulated. The proposed multi resonant switched capacitor buck converter (MRSCBC) can resolve these challenges while also providing output regulation. Switch mode power supplies exhibit high electromagnetic noise and with an increased number of switches in an MRSCBC, controlling EMI noise and compatibility is essential. This thesis will focus on the use of PCB design and software simulations to optimize electromagnetic interference (EMI) and parasitic elements in the traces to improve the robustness of an MRSCBC. 


\section{ACKNOWLEDGMENTS}

I would like to acknowledge Dr. Mohamed Badawy whose networking made the research project this thesis is based on possible. Badawy provided consistent direction and leadership to the research and pushed goals forward. Equal acknowledgements go to Anthony Chan who helped collaborate work between his team and the research team at San Jose State University (SJSU). Acknowledgements go to Jason $\mathrm{Ku}$ (Chih Sen $\mathrm{Ku}$ ) who worked on designing the feedback control of the multi resonant switched capacitive buck converter this thesis is based on. Jason exhibited a substantial work ethic which advanced the project forward. Devon Kind Provided work outside the scope of the thesis on the research project and acknowledgment to his work as part of the research team. Our collective effort allowed for the design and prototype of a new DC/DC converter achieving high efficiency and output voltage regulation in our simulations. Final academic acknowledgements go to the professors at SJSU. Acknowledgement to Professor Thomas Wrappe who taught much on engineering ethics and technical writing and Dr. Simon Tian whose power electronics class streamlined the design of this converter.

This thesis was completed during the coronavirus pandemic and the economic collapse of my home country of Lebanon. Acknowledgements go to the family and friends whose support allowed me to complete my degree and graduate. My success in completing my graduate degree is the success of their efforts. 


\section{TABLE OF CONTENTS}

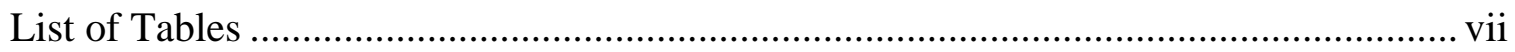

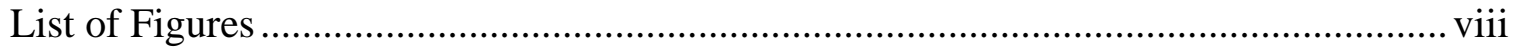

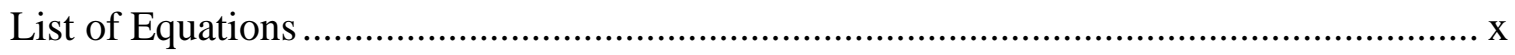

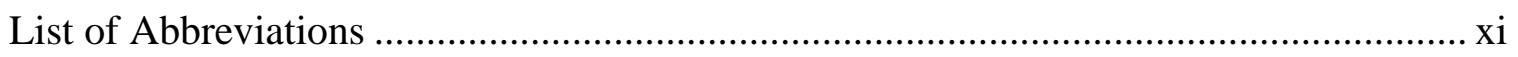

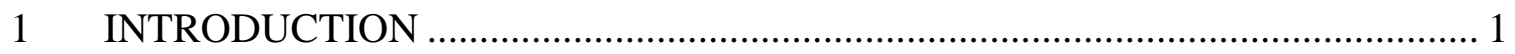

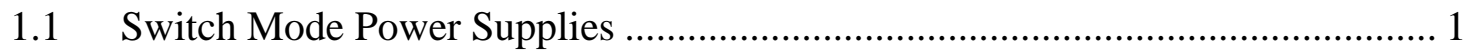

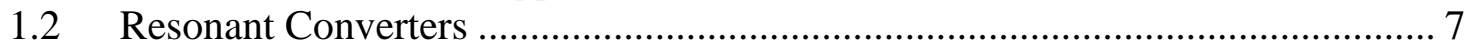

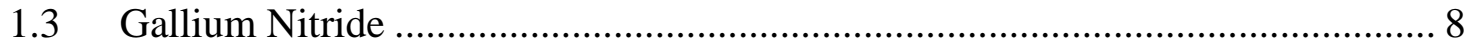

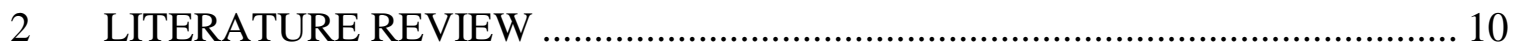

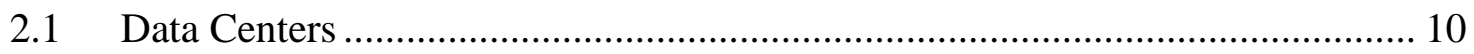

2.2 Intermediate Bus Converter .......................................................................... 10

2.3 Proposed Converter .................................................................................. 11

3 MULTI RESONANT SWITCH CAPACITIVE BUCK CONVERTER

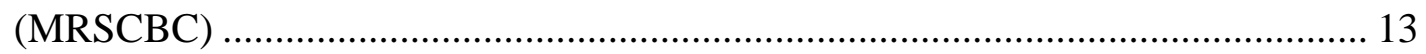

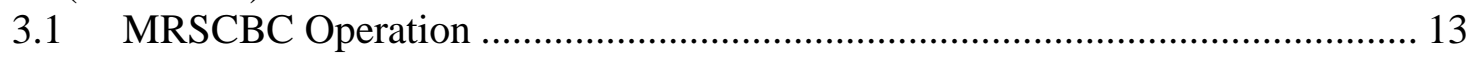

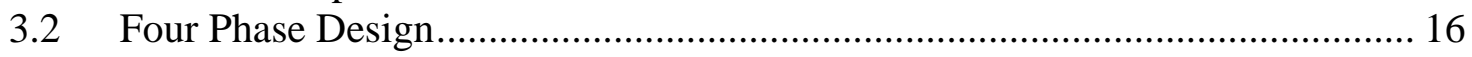

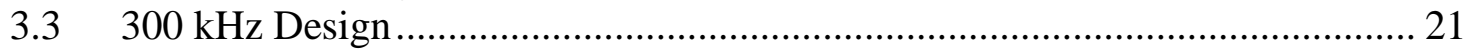

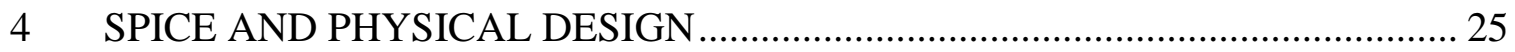

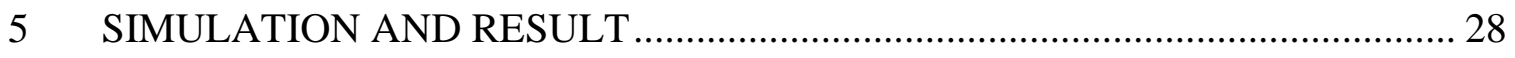

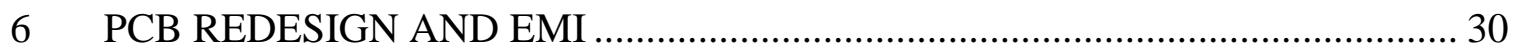

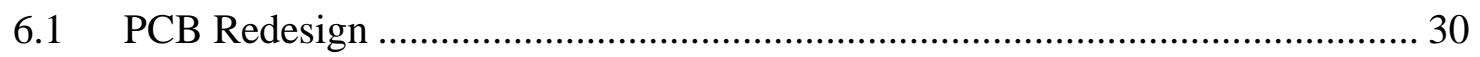

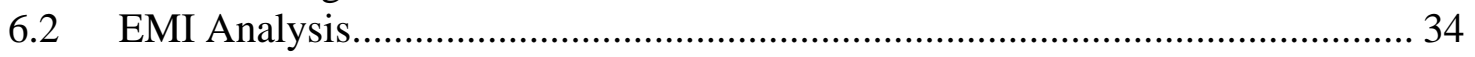

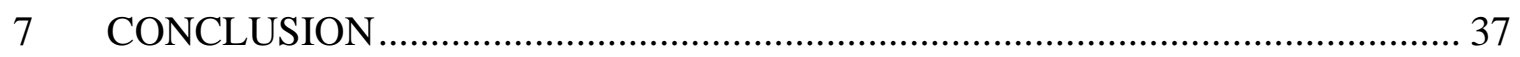

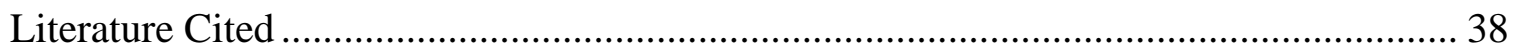




\section{List of Tables}

Table 1. Efficiency of Converter for Four Phased Interleaved MRSCBC. ................. 12

Table 2. Comparison of Phase Numbers for MRSCBC. .......................................... 18

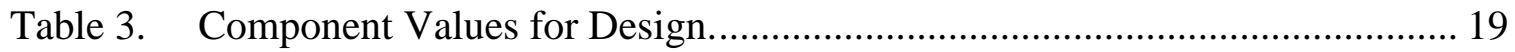

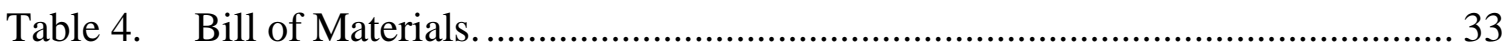




\section{List of Figures}

Fig. 1. Boost converter schematic...................................................................... 1

Fig. 2. Comparison of inductor size and current for single and two-phase

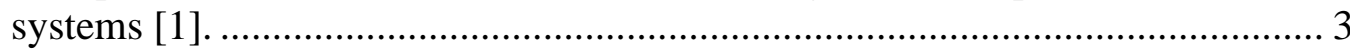

Fig. 3. Voltage overshoot comparison of single and multi-phase systems [1]............ 3

Fig. 4. Example of circulating current in multi-phase systems [1].......................... 4

Fig. 5. Visual comparison of three voltage regulation techniques [2] ........................ 5

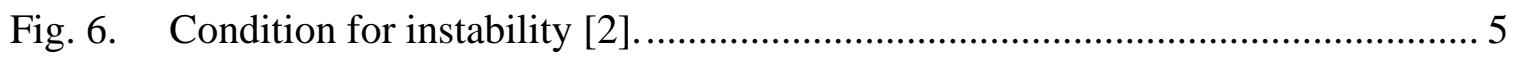

Fig. 7. Comparison of unstable (left) and stable (right) output voltages [2]............... 6

Fig. 8. Depiction of critical condition on bode plot (left) and Nyquist plot (right) [3]. . 7

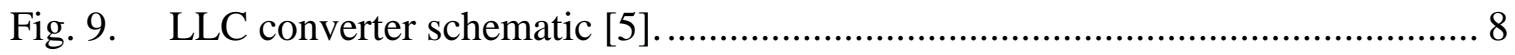

Fig. 10. Silicon to GaN transition with capabilities improvements [9]........................ 9

Fig. 11. Voltage and Rdson improvements of GaN compared to silicon ( $\mathrm{Si})$ [10].......... 9

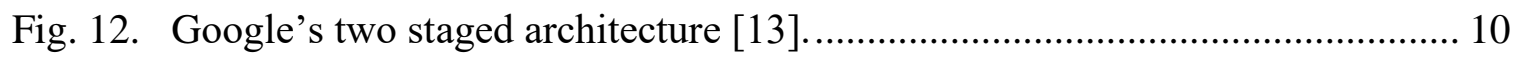

Fig. 13. Composite modular power delivery architecture (COMPDA) [14]................ 11

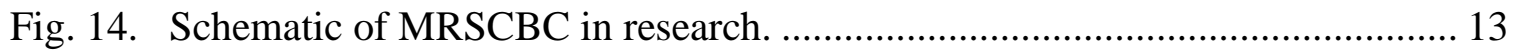

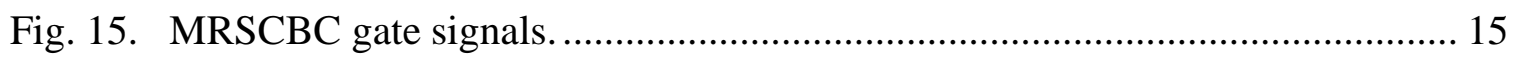

Fig. 16. Four-phased MRSCBC with peak current-mode control. .............................. 17

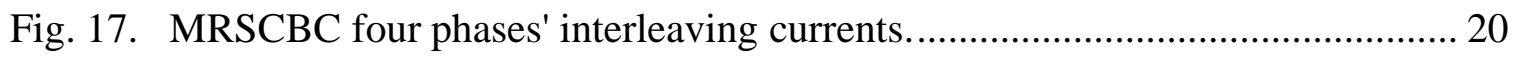

Fig. 18. MRSCBC transient response showing output voltage and output current. ....... 20

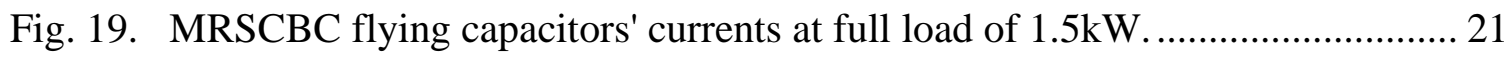

Fig. 20. Efficiency comparison of multi-phased MRSCBC at $1.5 \mathrm{~kW}$ output power. .... 21

Fig. 21. Fly capacitor current change with respect to resonant and switching

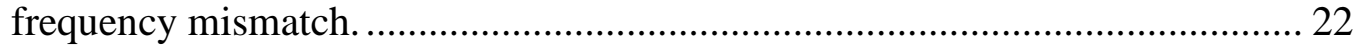

Fig. 22. Efficiency comparison of $300 \mathrm{kHz}$ and $500 \mathrm{kHz}$ design.............................. 23 
Fig. 23. Output voltage and inductor interleaved current during startup; (Y-axis shared between current and voltage signals).

Fig. 24. Output voltage of designed MRSCBC

Fig. 25. Workflow diagram of the technical design approach used in this paper.......... 25

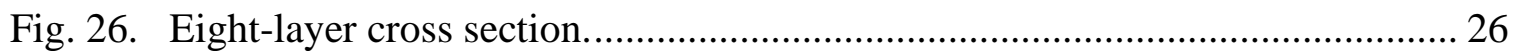

Fig. 27. First and final layer of the initial design highlighting component placement... 27

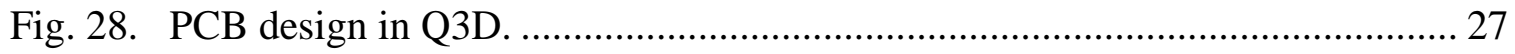

Fig. 29. Spice model of the parasitic elements in the designed PCB........................... 28

Fig. 30. Left to right: 1 . circuit failure to start with high parasitic inductance; 2. circuit startup with lowered inductance in gate drive traces. 3. circuit Startup with lowered inductance in control and gate drive traces.

Fig. 31. Routing comparison of gate driver output with the old design on the left and new design on the right.

Fig. 32. Thermal vias underneath the mosfets. ....................................................... 31

Fig. 33. Height comparison of original design (left) and redesign (right)................... 31

Fig. 34. Power capacitor size comparison between original (left) and redesign (right). 31

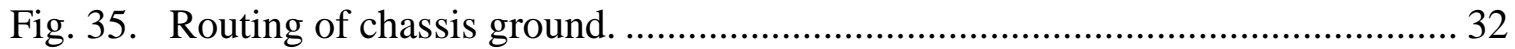

Fig. 36. Overall design comparison highlighting compactness between original (left)

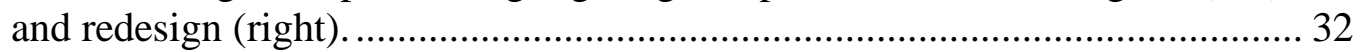

Fig. 37. Output of PSpice simulations with redesign parasitics. ................................ 32

Fig. 38. PSIM model with parasitic inductances in the power traces. .......................... 35

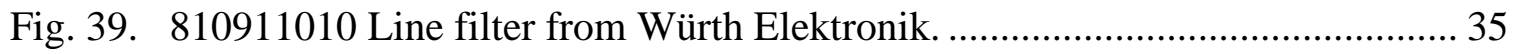

Fig. 40. EMI results of simulation shown passing CISPR 22 standards....................... 36 


\section{List of Equations}

Equation 1. Inductance to current ripple proportionality …................................... 2

Equation 2. Capacitance to voltage change proportionality ..................................... 2

Equation 3. Capacitance comparison for stability............................................. 14

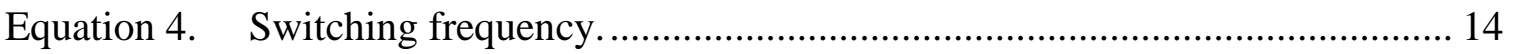

Equation 5. Deadtime calculation for secondary resonant circuit. ............................. 14

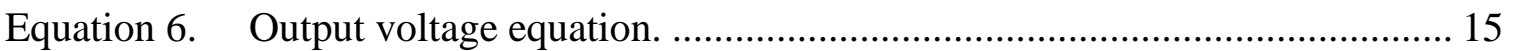

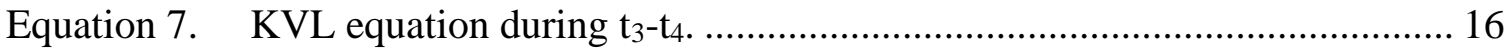

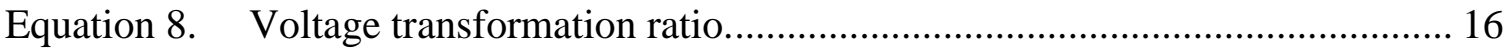

Equation 9. Minimum buck inductance calculation equation.................................... 16

Equation 10. Output capacitance calculation equation............................................ 16 


\section{List of Abbreviations}

POL - Point of Load

VR - Voltage Regulator

PSU - Power Supply Unit

IBC - Intermediate Bus Converter

COMPDA - Composite Modular Power Delivery Architecture

ZVS - Zero Voltage Switching

ZCS - Zero Current Switching

MRSCBC - Multi Resonant Switched Capacitive Buck Converter

MRSCC - Multi Resonant Switched Capacitive Converter

EMI - Electromagnetic Interference

SMPS - Switch Mode Power Supply

GaN - Gallium Nitride 


\section{INTRODUCTION}

\subsection{Switch Mode Power Supplies}

DC-DC converters are a type of power electronic circuits which are used as power supplies. The converters achieve voltage transformation using electrical elements such as mosfets and often inductors. Buck converters are a popular and simple example for stepdown voltage transformation using an inductor. In boost converters, however, the inductor is charged during off time and then discharged with the supply to produce a higher voltage on its output. Fig. 1 showcases an example of the DC-DC converter. Inside Fig. 1 is the schematic of a boost converter where $\mathrm{L}$ is the inductor, $\mathrm{Q}$ is the switching element, $\mathrm{D}$ is the diode, and $\mathrm{C}$ is the output capacitor.

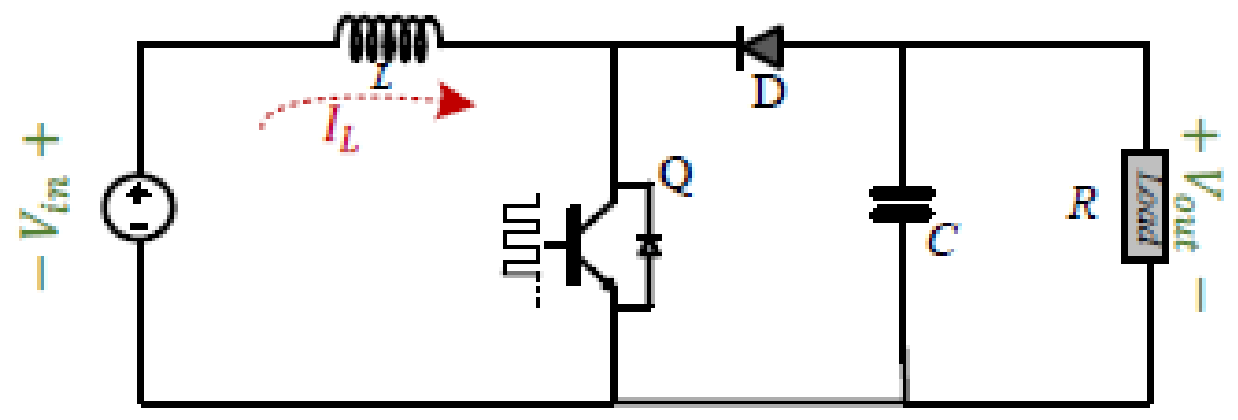

Fig. 1. Boost converter schematic.

When operating as power supplies, DC-DC converters are called switch-mode power supplies (SMPS) often used to power consumer electronics. The switching elements have typically been Mosfets using silicon technology. The popularity of silicon is due to the mature technology process and cheaper cost compared to other technologies such as gallium nitride. Power adapters are a popular example of SMPS which usually utilize flyback converters. 
When operating, switch-mode power supplies have multiple parameters surrounding their operation. The switching element, usually a mosfet, is primarily responsible for the transformation ratio of the voltage between its input and output. The duty cycle of the switching controls energy flow duration and direction in a SMPS. The inductor has a complex role that differs depending on the converter topology. Some topologies do not use a discrete inductor. Flyback, forward, and push-pull converters rely on leakage inductances inside their isolation transformers. Commonly, the inductance value is responsible for the ripple current value across it which can change a converter's mode of operation between continuous conduction mode (CCM) and discontinuous conduction mode (DCM). Finally, the output capacitance maintains a constant output voltage. The capacitance value is responsible for the voltage ripple on its output. Parasitic capacitances and inductances exist; however, their scope remains outside this thesis. Eqns. 1 and 2 are the equations for current ripple proportionality to inductance and voltage ripple proportionality to capacitance, respectively.

Equation 1. Inductance to current ripple proportionality

$$
L=V \times \frac{d i}{d t}
$$

Equation 2. Capacitance to voltage change proportionality

$$
I=C \frac{d v}{d t}
$$

Two important design considerations for a SMPS are the addition of multi-phase operation and output voltage regulations. The multi-phase design offers advantages in the form of smaller inductors for resonant circuits as in Fig. 2, and improved voltage 
overshoot during transients as in Fig. 3 [1]. Multi-phase designs, however, do suffer from susceptibility to circulating current as shown in Fig. 4 [1].
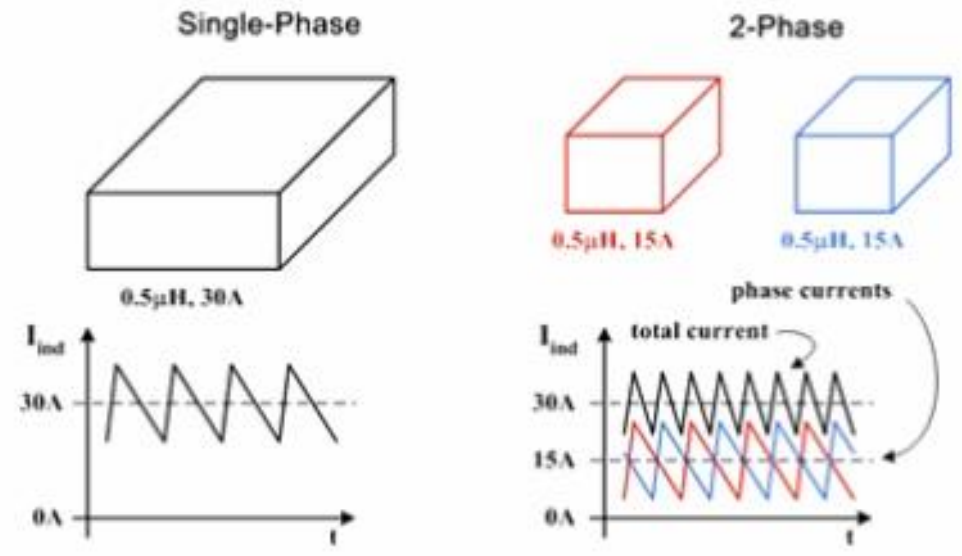

Fig. 2. Comparison of inductor size and current for single and two-phase systems [1].
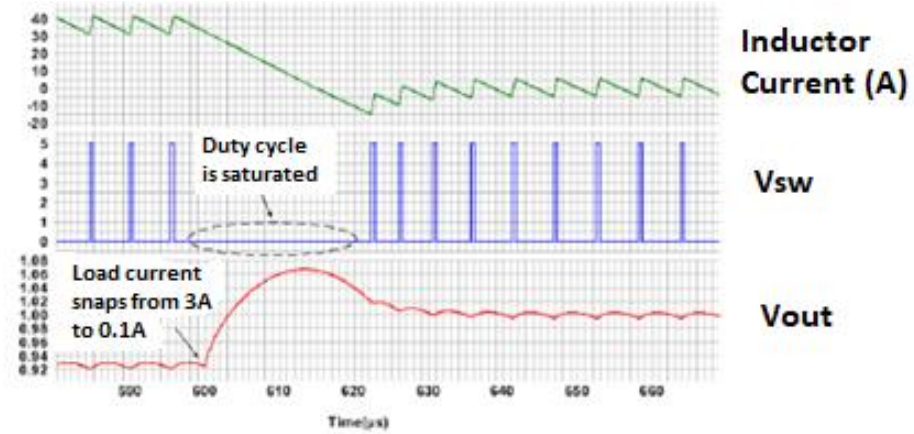

Vsw

Vout

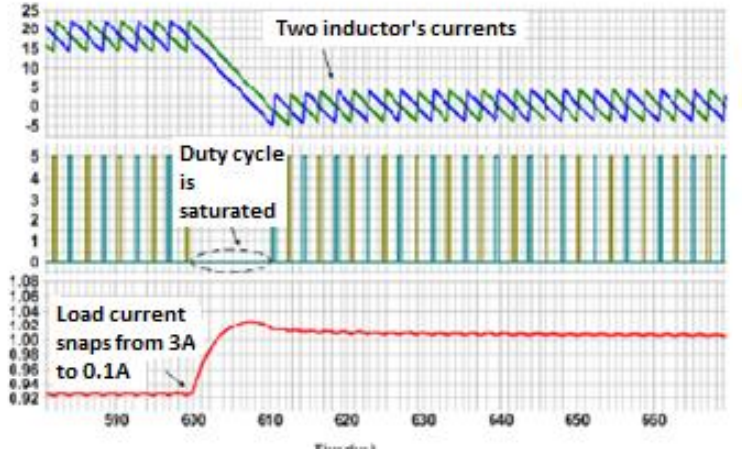

Inductor

Current (A)

Vsw

Vout

Fig. 3. Voltage overshoot comparison of single and multi-phase systems [1]. 


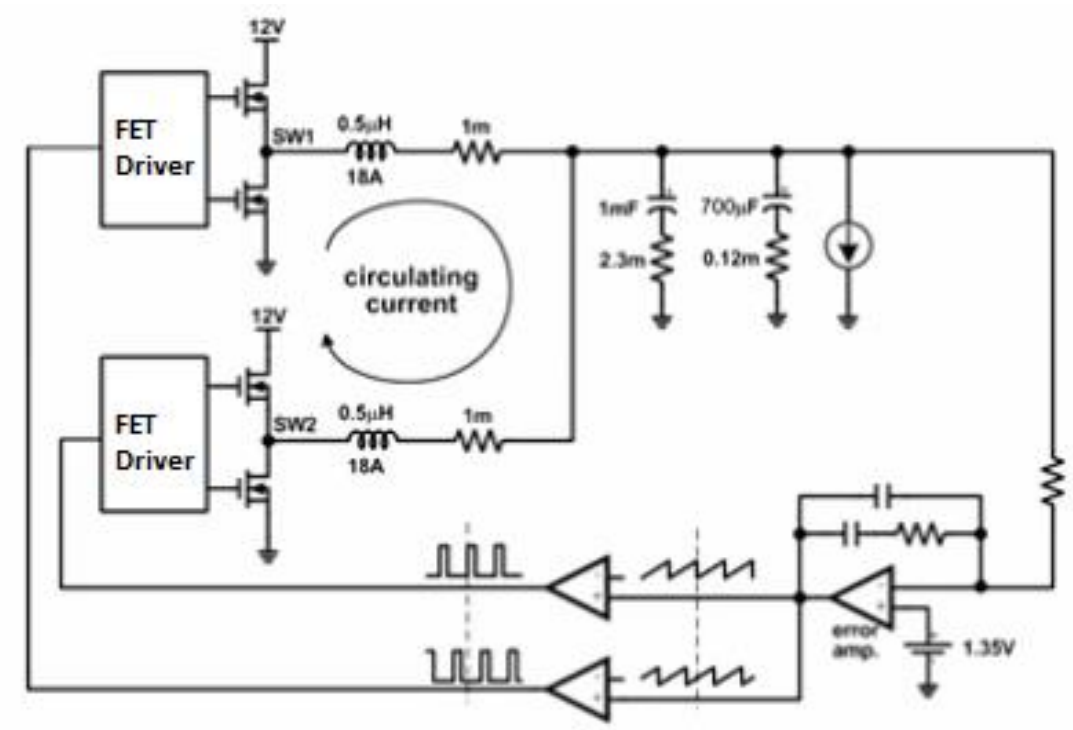

Fig. 4. Example of circulating current in multi-phase systems [1].

There are three types of voltage regulation schemes that exist which are fixed ratio, semi-regulated, and fully regulated converter outputs [2]. In a fixed ratio SMPS, the output voltage is not regulated and changes with any input voltage perturbation. This type of converter operates with a wide output voltage range and a small input voltage range [2]. The semi-regulated SMPS offers partial regulation which is an improvement over nonregulated outputs. The output voltage is regulated based on perturbation to the input voltage. The input voltage of the semi-regulated converter can maintain a wide range, while output voltage maintains a smaller range relative to the input [2]. The last regulation scheme is the fully regulated converter. The output voltage is regulated into a fixed value regardless of perturbations on the input while output perturbations are canceled. The fully regulated converter can handle a large input voltage range [2]. Fig. 5 depicts the three regulation schemes as well as the input and output voltage range of each. 


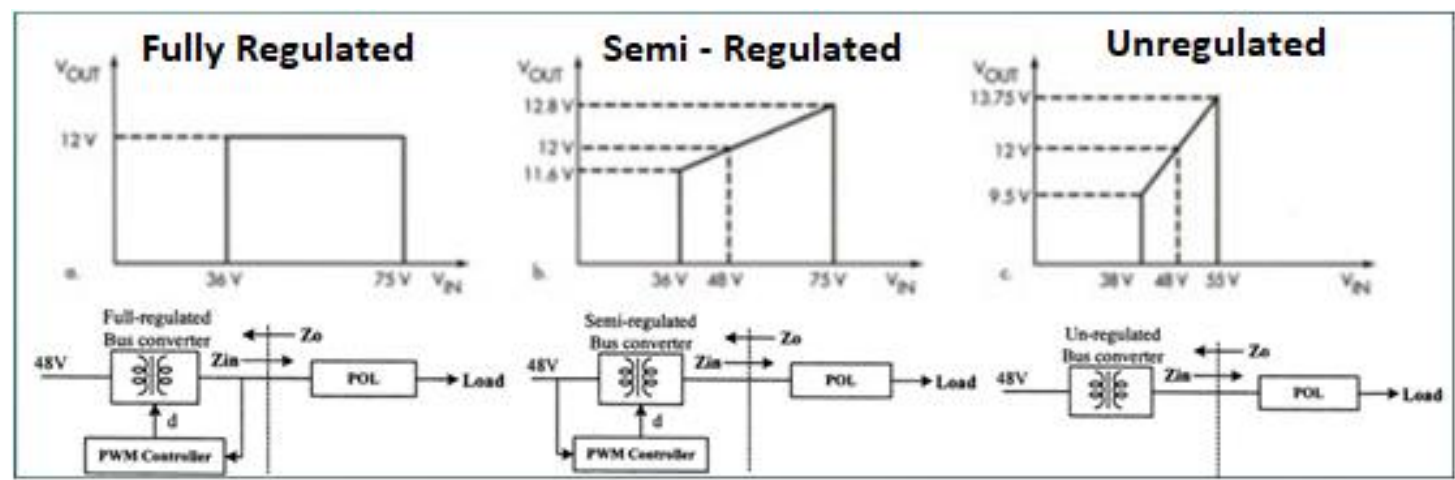

Fig. 5. Visual comparison of three voltage regulation techniques [2].

Another concert affecting regulation choice is stability. Regulation instability refers to the presence of voltage oscillations during operation [2]. A regulator which is designed to be stable in standalone operation may show oscillatory and unstable behavior once connected to a load [2]. Instability in operation is due to overlap in the converter output impedance and load input impedance [2]. The presence of impedance overlap, shown in Fig. 6, triggers instability for output voltage [2].

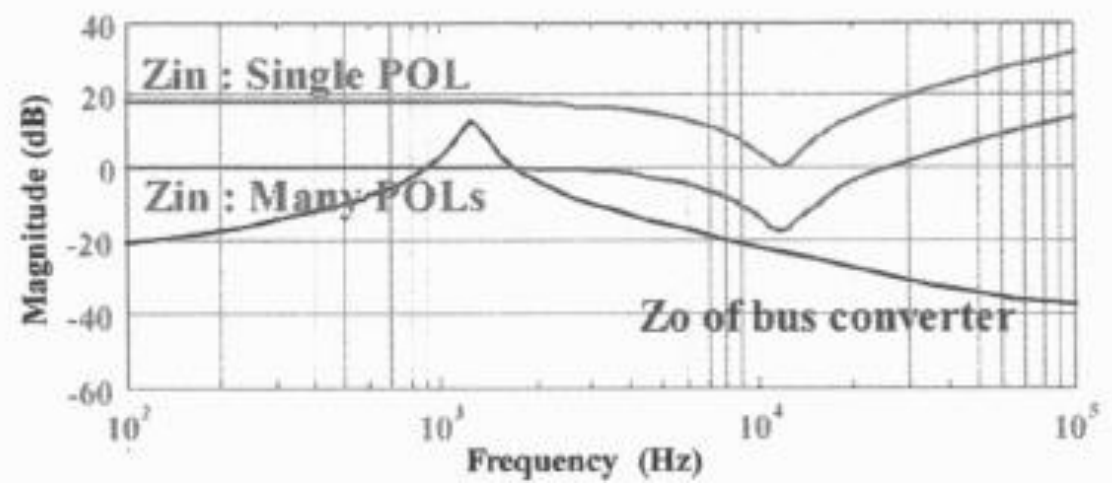

Fig. 6. Condition for instability [2].

If the number of parallel loads connected to the converter is high, then their input impedance could become lower than the converter's output impedance. Both nonregulated and semi-regulated control topologies suffer from this issue while fully regulated converters do not [2]. Due to the higher bandwidth in fully regulated control, 
the peak impedance is lowered and no overlap between the output and input impedance occurs. Fig. 7 displays a comparison between stable converter output voltage and unstable converter voltage oscillations.
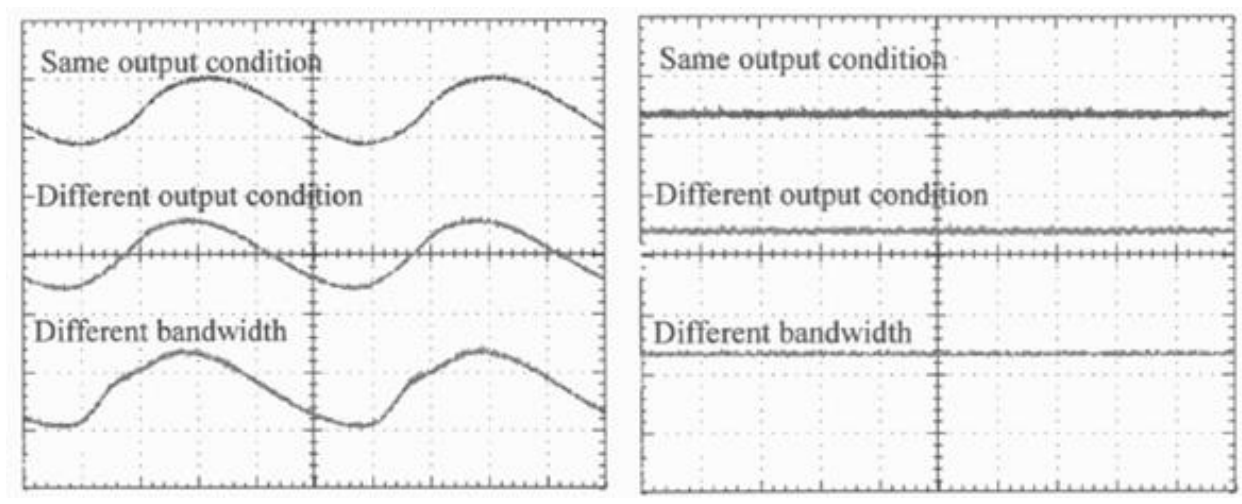

Fig. 7. Comparison of unstable (left) and stable (right) output voltages [2].

Further analysis of the bode plots shows that when the output impedance of the converter exceeds the low-frequency input impedance of its load then operation slides into unstable regions [3]. This behavior is observed through a nyquist plot. Stable operation observers no clockwise encirclements of the $(-1,0)$ point which is the critical point for stability [3]. Since the nyquist plot flows in a clockwise direction, if it does encircle the critical point then the system becomes unstable. When the output impedance of the converter is equal to the low-frequency input impedance of the load connected, we observe marginal stability as in Fig. 8 [3]. 

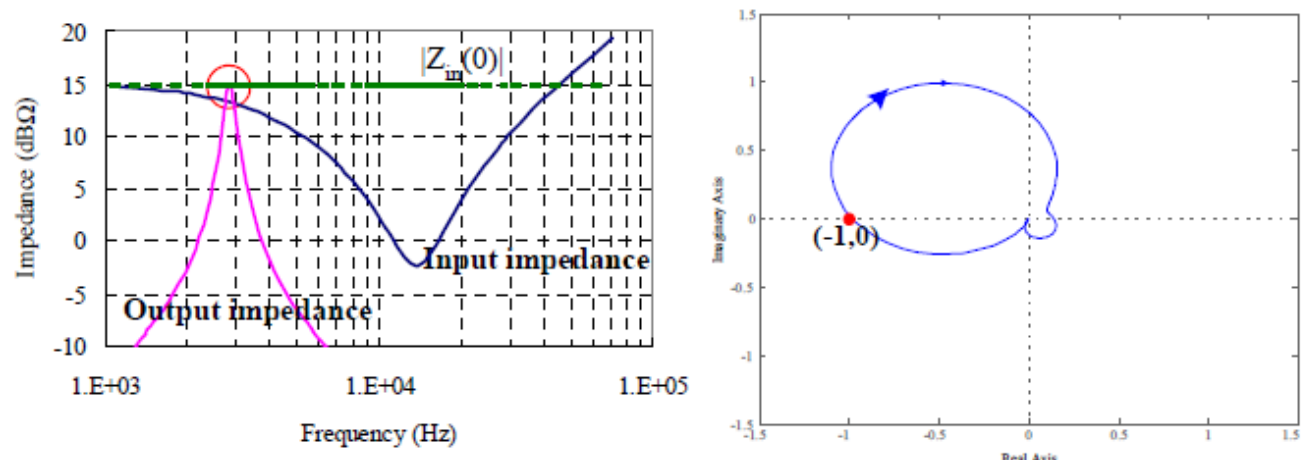

Fig. 8. Depiction of critical condition on bode plot (left) and nyquist plot (right) [3].

There exist solutions to maintain a stable output for each regulation mode. In fixedratio converters the output capacitance can be increased [3]. In high power and energy dense application this is impractical due to the large number of capacitors required. Reducing the inductor size and increasing the duty cycle is another solution which improves system stability. For semi-regulated operation, however, the duty cycle is variant, and as a result, the only way to improve output stability is by utilizing larger output capacitances [3].

\subsection{Resonant Converters}

A variation of DC-DC converters is resonant converters. Resonant converters are favorable for high-power applications. One popular topology is the LLC resonant converters. LLC converters hold a multitude of benefits that are advantageous in highpower applications. LLC converters benefit from high power density and high efficiency which are important for high power [4]. Zero voltage switching (ZVS) and zero current switching (ZCS) is another benefit to the LLC topology which allows to reduce switching losses [5]. Fig. 9 presents the schematic of an LLC converter and highlights the LLC tank. 


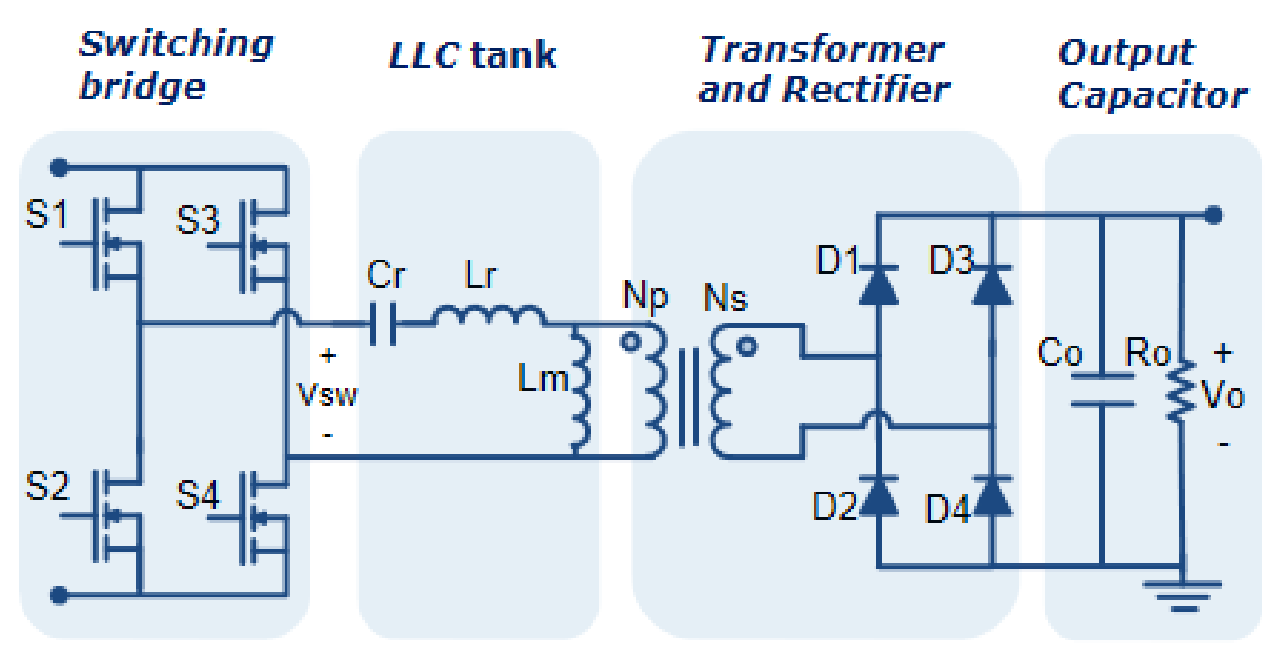

Fig. 9. LLC converter schematic [5].

\subsection{Gallium Nitride}

A new technology popularizing in the power electronics and SMPS industry is gallium nitride $(\mathrm{GaN}) . \mathrm{GaN}$ is used for wide-bandgap semiconductors that are implemented in transistors and integrated analog circuits. GaN offers improved efficiency, improved switching speeds, and higher breakdown voltages [6]. When implemented, GaN can reduce the size footprint of a package while maintaining the same power and voltage breakdown capabilities or allow for higher capabilities using the same size package. GaN technology does suffer from some drawbacks. Parasitic inductance inside traces leading to a GaN transistor can cause issues such as ringing and increased EMI. As a result, strong efforts are needed when designing a layout for a GaN switching circuit [7]. The improvements and popularity of GaN are a cause to include it in any analysis of a new DC-DC converter topology. The industry is currently shifting towards GaN and companies such as Power Integrations are designing their own GaN implementations called "PowiGaN" [8]. Fig. 10 presents the improved switching and power capabilities of GaN compared to traditional silicon transistors. Fig 11. showcases the voltage and on- 
resistance (Rdson) improvements of GaN transistor over traditional silicon-based transistors.

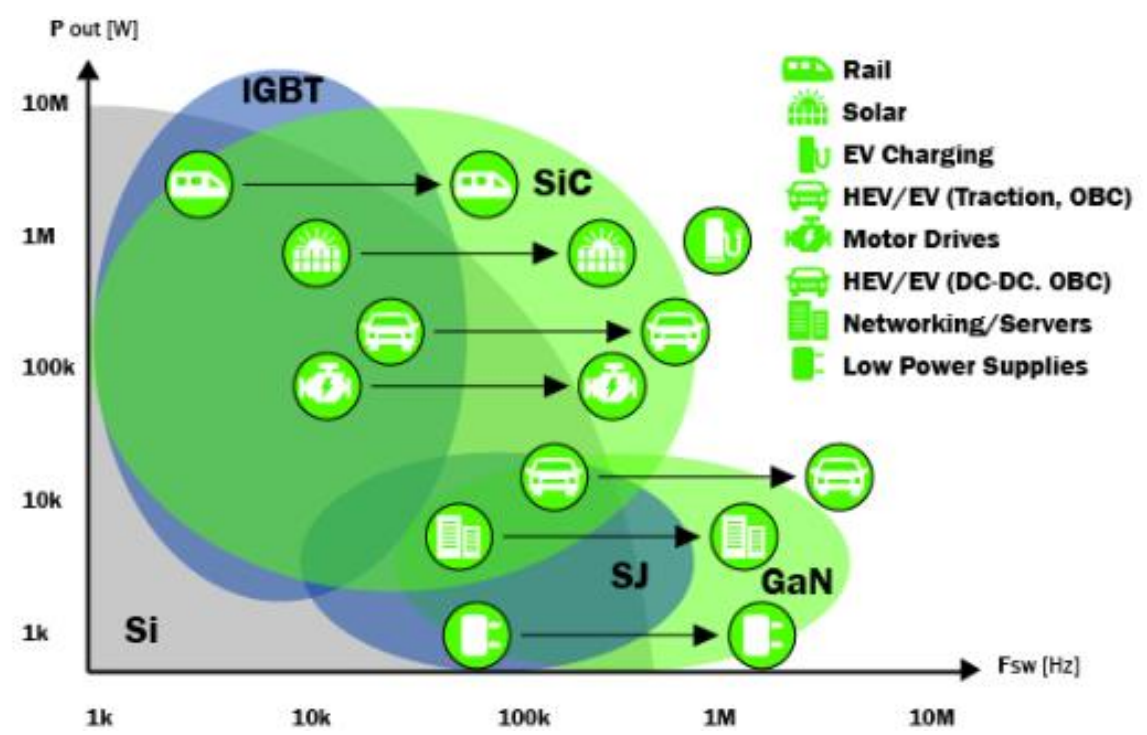

Fig. 10. Silicon to GaN transition with capabilities improvements [9].

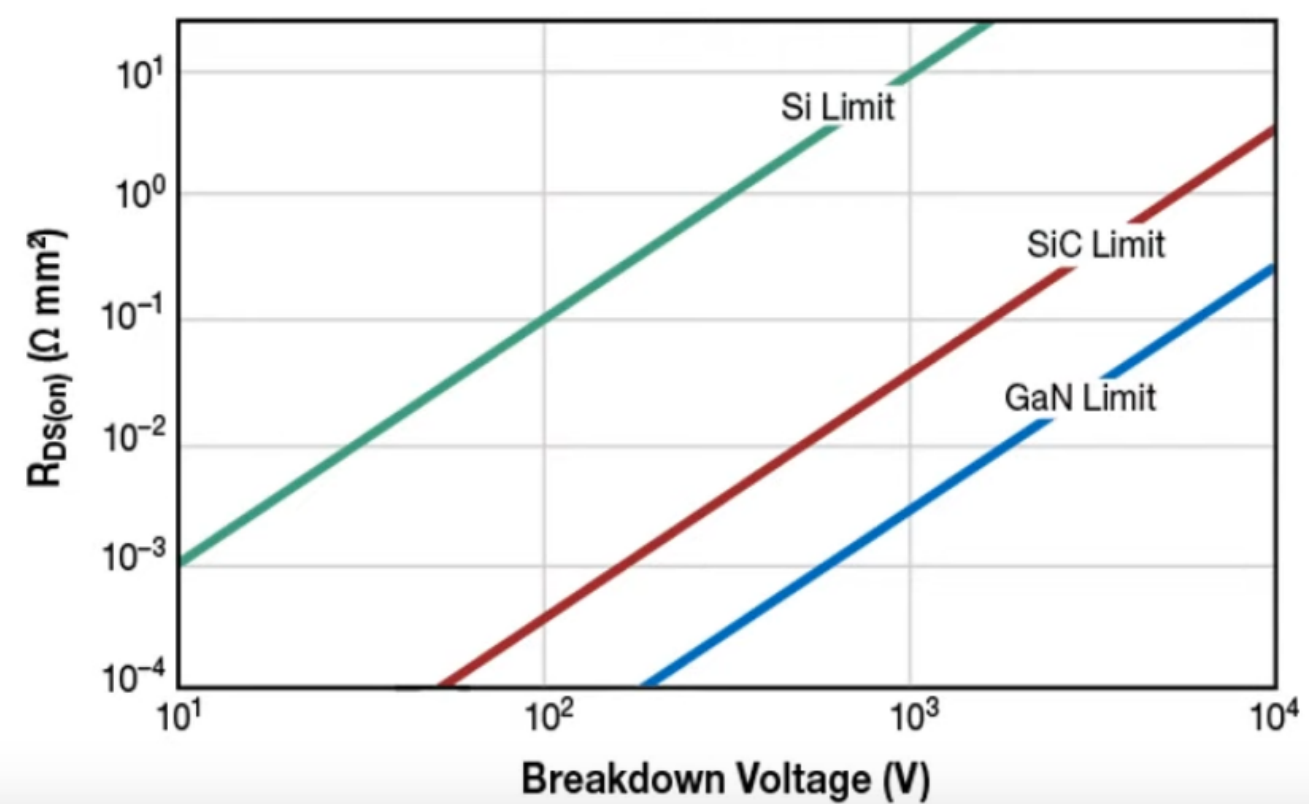

Fig. 11. Voltage and Rdson improvements of GaN compared to silicon ( $\mathrm{Si}$ ) [10]. 


\section{LITERATURE REVIEW}

\subsection{Data Centers}

Data centers, which consume $2 \%$ of total power usage in the US, can improve their energy consumption by reducing their conduction losses [11]. Data center racks can be rated up to $15 \mathrm{~kW}$ where each rack contains up to $220 \mathrm{~A}$ rated current at point of load voltages of $1.85 \mathrm{~kW}$ [12]. Raising the DC bus voltage of data centers to $48 \mathrm{~V}$ diminishes distribution losses and is a popular area of industry research [13]. A $48 \mathrm{~V}$ bus converter is located between the power supply unit (PSU) and the $12 \mathrm{~V}$ servers in two-staged architectures as illustrated in Fig. 12 [14]

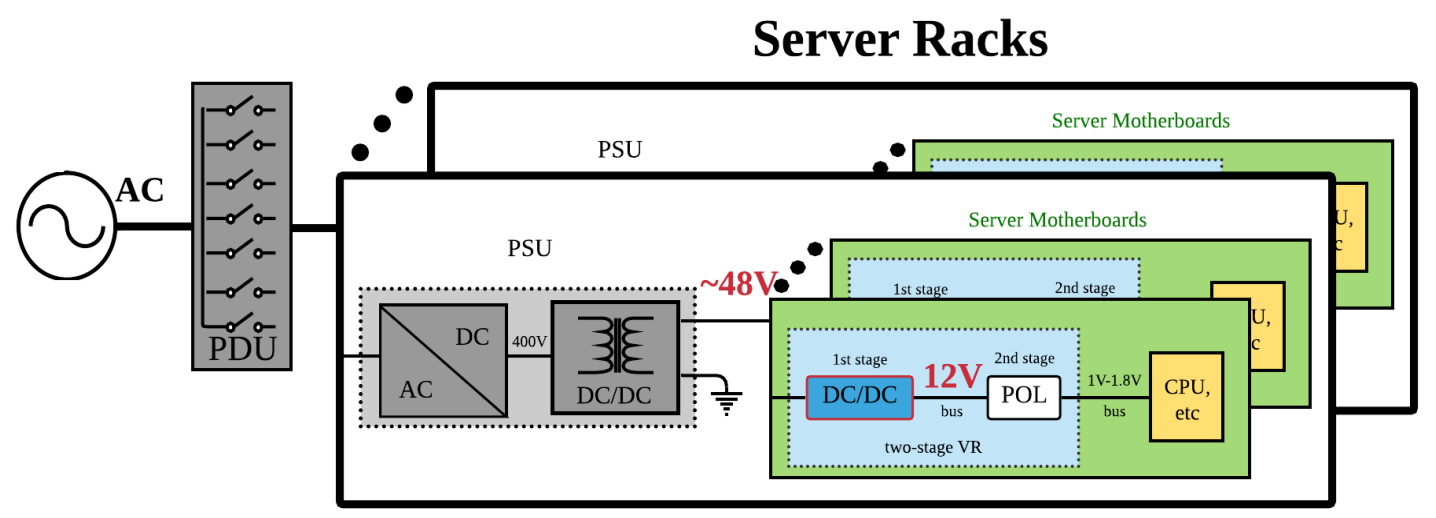

Fig. 12. Google's two staged architecture [13].

\subsection{Intermediate Bus Converter}

The design of intermediate bus converters (IBC) has high demands and limitations for two-staged regulator structures. The data center market is competitive where power density and efficiency are a design priority [15]. The market for $48 \mathrm{~V}$ to $12 \mathrm{~V}$ IBC contains a variety of power converter topologies. A non-isolated fixed-ratio DC/DC converter by Vicor Power steps down a $48 \mathrm{~V}$ input voltage to $12 \mathrm{~V}$ through a high-frequency LC tank 
converter with an efficiency up to $97.9 \%$ and power density reaching $4.5 \mathrm{~kW} / \mathrm{in}^{3}[16]$. Another different topology is a composite modular power delivery architecture (COMPDA) based switched-tank converter (STC) which was presented by the State University of North Dakota [14]. Fig. 13 showcases the COMPDA architecture.

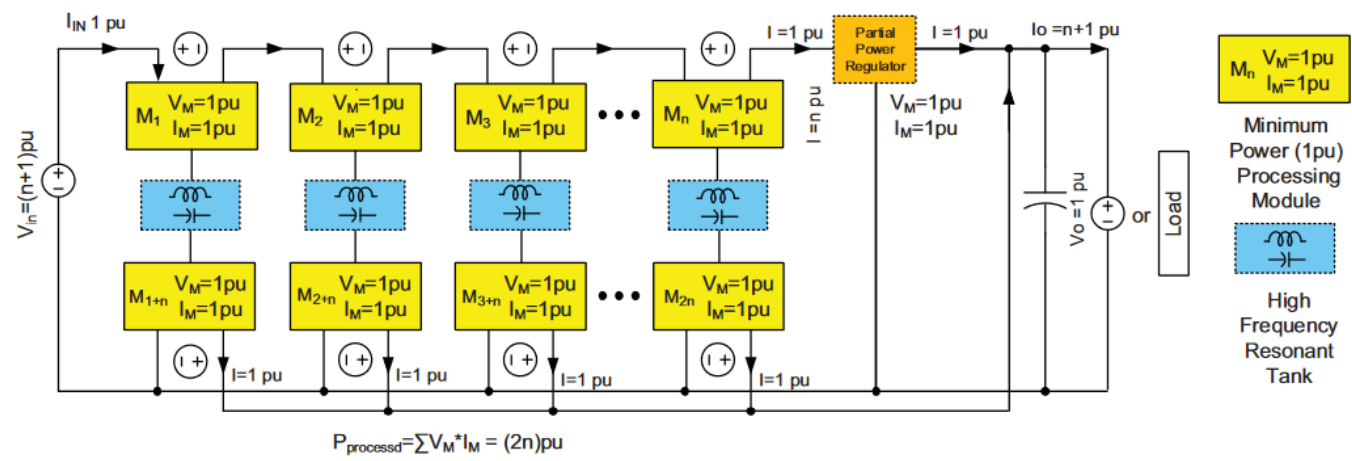

Fig. 13. Composite modular power delivery architecture (COMPDA) [14].

The COMPDA achieves zero voltage switching (ZVS) and zero current switching (ZCS) which maintains low voltage stress for all the components and utilizes a smaller power delivery module. The efficiency reaches $98.55 \%$ peak efficiency and a $750 \mathrm{~W} / \mathrm{inch}^{3}$ power density. These converter topologies, however, lack voltage regulation on their $12 \mathrm{~V}$ output.

\subsection{Proposed Converter}

Resonant converters are a popular area of research [15]. A regulated two-staged multiresonant multi-phased switched-capacitor-buck converter (MRSCBC) is in the research phase at San Jose State University, and it achieves high efficiency and power density for the two-staged VR structure while regulating the $12 \mathrm{~V}$ output. Research simulation results suggested efficiency numbers up to $98 \%$ at $1.5 \mathrm{~kW}$, as depicted in Table 1 . The MRSCBC is made up of two cascaded converters. The first is a multi-resonant switched-capacitor 
converter (MRSCC) which halves the input voltage by a fixed ratio. The second cascaded stage of the converter is a synchronous buck converter that can step down the input voltage to a regulated $12 \mathrm{~V}$ output using peak current-mode control for equal current sharing of the multi-phases used in the design. There is potential for the MRSCBC converter to be competitive in the data center market.

Table 1. Efficiency of Converter for Four Phased Interleaved MRSCBC.

\begin{tabular}{|c|c|c|c|}
\hline Input Power & Output Power & Efficiency & Dissipated Power \\
\hline $1.5224 \mathrm{~kW}$ & $1.49813 \mathrm{~kW}$ & $98.41 \%$ & $24.266 \mathrm{~W}$ \\
\hline
\end{tabular}




\section{MULTI RESONANT SWITCH CAPACITIVE BUCK CONVERTER (MRSCBC)}

\subsection{MRSCBC Operation}

The MRSCBC consists of an MRSCC which is cascaded by a buck converter on its output to provide regulation. Fig. 14 showcases the MRSCBC schematic.

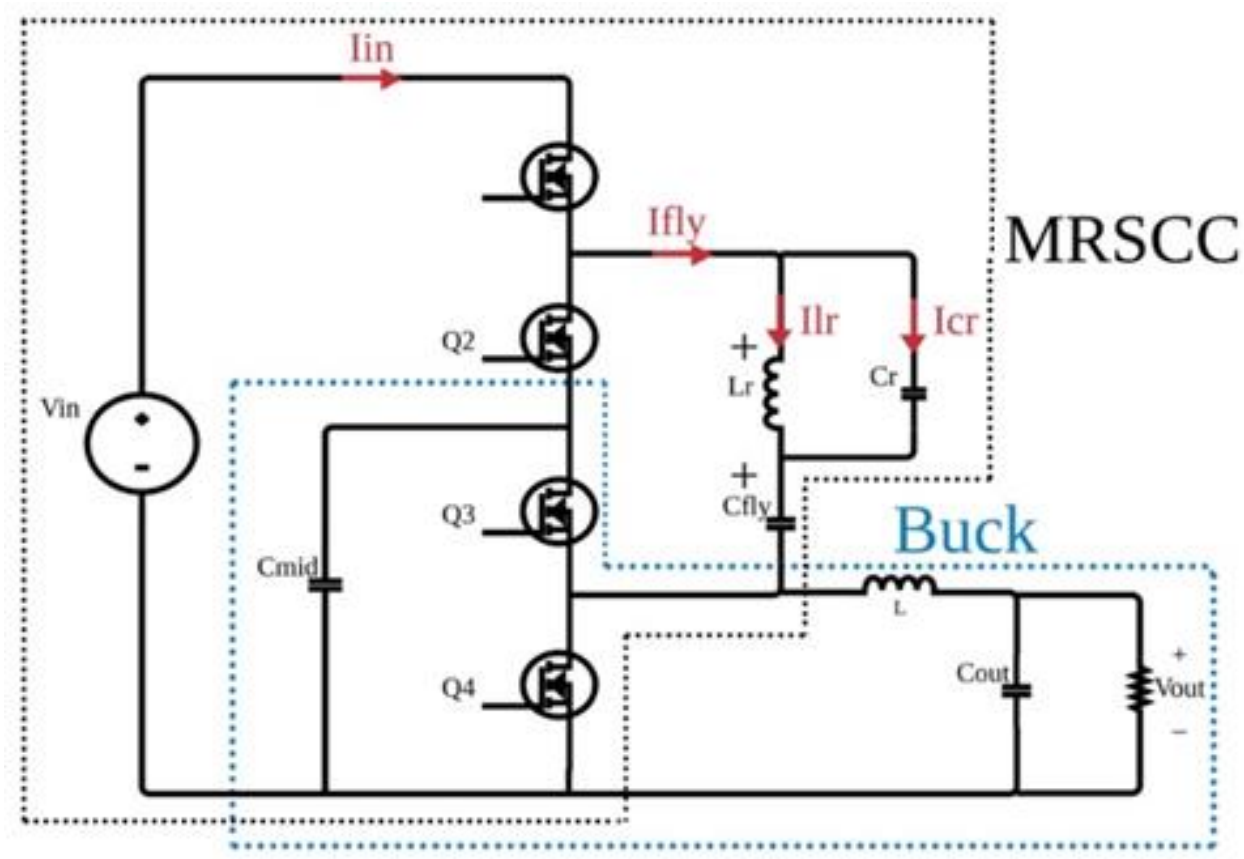

Fig. 14. Schematic of MRSCBC in research.

The MRSCC is characterized by high efficiency and power density but remains unable to regulate its output due to fixed ratio conversion [16]. A small inductor $L_{r}$ placed in series with the fly capacitor $\mathrm{C}_{\text {fly }}$ prevents hard charging and eliminates high conduction losses. The inductor $\mathrm{L}_{\mathrm{r}}$ with capacitor $\mathrm{C}_{\text {fly }}$ function as a resonant tank to control the charging current at a resonant frequency $f_{0}$. However, it is difficult to match the resonant tank frequency to the switching frequency due to components values' variations. Class I capacitors, recommended for resonant capacitors, keep resonant frequencies fixed with 
respect to bias voltages. Class I capacitors have, however, part to part variation of $20 \%$ at worst case [17]. To prevent negative inductor current turn-off in the resonant tank and increase immunity to component variation due to resonant and switching frequency mismatch, the switching frequency $\mathrm{f}_{\mathrm{sw}}$ is selected higher than the nominal resonant frequency $f_{o}$ [17]. To handle inductor discharging, a capacitor $C_{r}$ much smaller than $C_{\text {fly }}$ forms a second high frequency resonant tank with the inductor to discharge the current in a controlled manner during the deadtime $t_{d}$ [17]. With higher switching frequency which increases immunity to component variation, the use of class II capacitors is allowed for $\mathrm{C}_{\text {fly }}$ [17]. $\mathrm{C}_{\text {fly }}$ needs to be larger than $\mathrm{C}_{\mathrm{r}}$ as depicted in Eqn. 3.

Equation 3. Capacitance comparison for stability.

$$
C_{r}<C_{f l y}
$$

Equation 4. Switching frequency.

$$
f_{s w}>f_{o}=\frac{1}{2 \pi \sqrt{L_{r} C_{f l y}}}
$$

Equation 5. Deadtime calculation for secondary resonant circuit.

$$
t_{d}=\pi \sqrt{L_{r} C_{r}}
$$

Eqn. 4 presents the calculation for the resonant frequency $f_{o}$ and illustrates the switching frequency $\mathrm{f}_{\mathrm{sw}}$ being higher. Eqn. 5 can be used to size the secondary resonant capacitor $\mathrm{C}_{\mathrm{r}}$. 


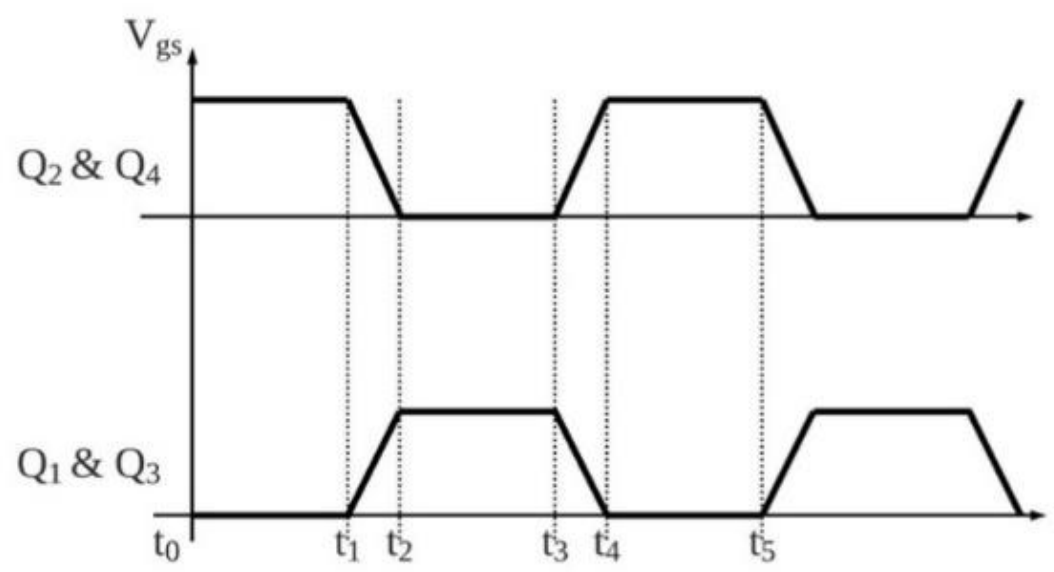

Fig. 15. MRSCBC gate signals.

The MRSCBC operates with two conduction cycles and one dead-time for a total of three switching phases. Fig. 15 depicts these switching phases. The secondary resonant tank $\mathrm{L}_{\mathrm{r}}$ and $\mathrm{C}_{\mathrm{r}}$ is isolated during the deadtime periods $\mathrm{t}_{1}-\mathrm{t}_{2}$ and $\mathrm{t}_{3}-\mathrm{t}_{4}$. During the deadtime, the resonant tank rings, and the current changes to the opposite direction by the time the dead time is over which eliminates voltage spikes from the main switching circuit. Gates $\mathrm{Q}_{2}$ and $\mathrm{Q}_{4}$ switch on while $\mathrm{Q}_{1}$ and $\mathrm{Q}_{3}$ switch off in periods $\mathrm{t}_{0}-\mathrm{t}_{1}$. During the mentioned period, the primary resonant tank is parallel with the output, and the flying capacitor $\mathrm{C}_{\mathrm{fly}}$ transfers its stored energy to the middle capacitor $\mathrm{C}_{\mathrm{mid}}$ and the output loads. Eqn. 6 calculates the output voltage.

Equation 6. Output voltage equation.

$$
V_{o u t}=V_{C f l y}+V_{L r}
$$

Gates $\mathrm{Q}_{2}$ and $\mathrm{Q}_{4}$ switch off, and $\mathrm{Q}_{1}$ and $\mathrm{Q}_{3}$ switch on during the period $\mathrm{t}_{3}-\mathrm{t}_{4}$. During $t_{3}-t_{4}$ the primary resonant tank and output are in series with the input supply and energy is transferred directly between the input and the output. Eqn. 7 presents the series 
KVL equation. The combination of Eqn. 6 and 7 produces Eqn. 8. Observation of the analysis shows how the first stage of the MRSCBC operates as a simple voltage divider that halves the input voltage.

Equation 7. KVL equation during $\mathrm{t}_{3}-\mathrm{t}_{4}$.

$$
-V_{\text {in }}+V_{c f l y}+V_{L r}+V_{\text {out }}=0
$$

Equation 8. Voltage transformation ratio.

$$
V_{\text {out }} \approx \frac{1}{2} V_{\text {in }}
$$

Equation 9. Minimum buck inductance calculation equation.

$$
L_{\min } \geq \frac{(1-D) R}{2 f_{S W}}
$$

Equation 10. Output capacitance calculation equation.

$$
C_{\text {out }}=\frac{(1-D)}{8 L \frac{\Delta V_{o}}{V_{o}} f_{S W}{ }^{2}}
$$

The buck converter which cascades the MRSCBC runs in continuous conduction mode and minimum buck inductor inductance $\mathrm{L}_{\min }$ is calculated through Eqn. 9. The parameters of Eqn. 9 are D, R, and $\mathrm{f}_{\mathrm{sw}}$ which are the duty ratio, load resistance, and switching frequency respectively. Eqn. 10 uses the desired output ripple voltage $\Delta \mathrm{V}_{\mathrm{O}}$ to calculate the output capacitor's capacitance $\mathrm{C}_{\text {out }}$ similar to a traditional buck circuit output.

\subsection{Four Phase Design}

The buck converter stage provides voltage regulation which improves the converter stability. Converter stability can be determined by the overlap between the converter 
output impedance and load input impedances [2]. If enough loads are connected in parallel to a converter their input impedance could lower to a value below the output impedance of the converter. In such a situation the converter output voltage begins to oscillate and exits stable operation. [3]. A fully regulated converter benefits from its ability to lower its output impedance through voltage regulation and reduces the chances of falling into unstable operation [2]. Full regulation is achieved through peak current mode control. Peak current-mode control is chosen for its large duty cycle range aiding in regulation stability, and popular use.

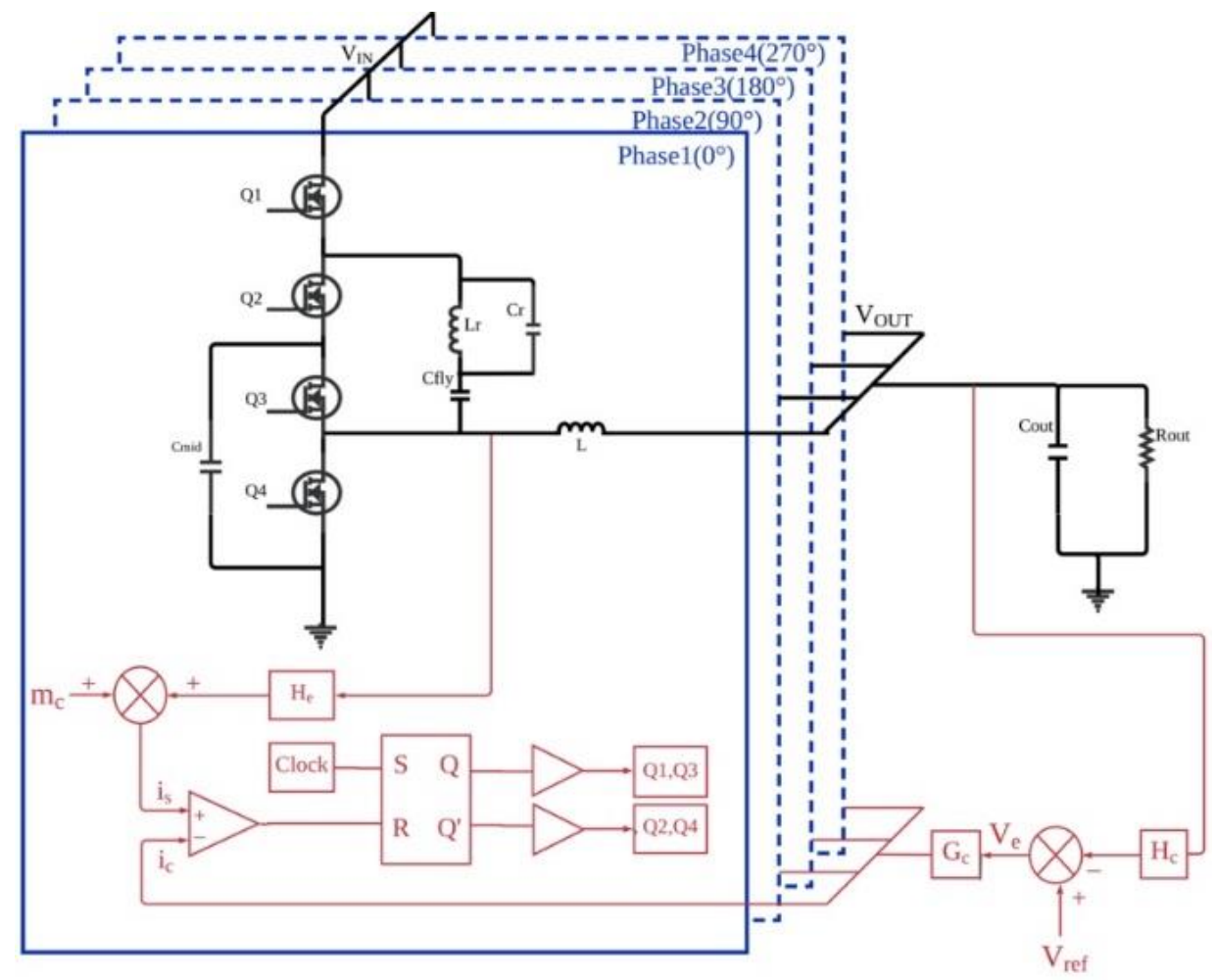

Fig. 16. Four-phased MRSCBC with peak current-mode control.

For large loads, the multi-phase operation is preferred as it keeps inductor sizes small due to current sharing. Balanced current sharing between phases can be achieved through 
peak current-mode control. Fig. 16 presents a simplified diagram of four-phased MRSCBC regulated through peak current mode control. Lowering the per-phase current reduces the ripple-current-rating requirement and reduces conduction losses and heat stress for capacitors, mosfets, and inductors in the design which also increases efficiency. Furthermore, the multi-phased design allows for interleaved current on the output which cancels high current ripple values [18]. The main drawback of multi-phased design as expected is the large number of components required as the power and gate drive elements are paralleled for each phase. Table 2 illustrates how many components are used per phase and the current reduction achieved through multi-phased design.

Table 2. Comparison of Phase Numbers for MRSCBC.

\begin{tabular}{|c|c|c|c|c|}
\hline \multicolumn{5}{|c|}{$\begin{array}{l}\text { Multi-Phased MRSCCB Converter at } 1.5 \mathrm{~kW} \text { Output } \\
\text { Power }\end{array}$} \\
\hline & $\begin{array}{l}\text { Single } \\
\text { Phase }\end{array}$ & $\begin{array}{l}\text { Two- } \\
\text { Phase }\end{array}$ & $\begin{array}{l}\text { Three } \\
\text { Phase }\end{array}$ & $\begin{array}{l}\text { Four } \\
\text { Phase }\end{array}$ \\
\hline $\begin{array}{l}\text { Total \# of } \\
\text { Inductors }\end{array}$ & 2 & 4 & 6 & 8 \\
\hline $\begin{array}{l}\text { Total \# of } \\
\text { Capacitors }\end{array}$ & $>4$ & $>8$ & $>12$ & $>16$ \\
\hline $\begin{array}{l}\text { Total \# of } \\
\text { MOSFETS }\end{array}$ & 4 & 8 & 12 & 16 \\
\hline $\begin{array}{l}\text { Current per } \\
\text { Phase (A) }\end{array}$ & 125 & 62.5 & 41.7 & 31.25 \\
\hline
\end{tabular}

For the converter design starting with the output and middle capacitors $\mathrm{C}_{\mathrm{o}}$ and $\mathrm{C}_{\mathrm{mid}}$ respectively, Würth Electroniks (WE) X7R ceramic capacitors are chosen with low ESR and ESL which helps control conduction losses and the high-frequency resonance. Ten ceramic capacitors are paralleled for each capacitor. Similar X7R ceramic capacitors are 
chosen for the fly capacitor $\mathrm{C}_{\mathrm{fly}}$ where twelve are paralleled. Infineon BSC032N04LS switches with low on-resistance mosfets are used to also to maintain low conduction losses. The buck converter utilizes an SER2011-202 rated $2 \mu \mathrm{H}$ inductor from Coilcraft which is rated for high peak and RMS current suitable for prototyping. UCC21520 isolated gate drivers safely switch two of the high-voltage power transistors without damaging the control logic circuit in each phase. Table 3. summarizes and continues the power stage's component selection for the design.

Table 3. Component Values for Design.

\begin{tabular}{lcl}
\hline Components Parameters & Item & Values \\
\hline Input DC Voltage & $V_{\text {in }}$ & $48 \mathrm{~V}$ \\
Output DC Voltage & $V_{o}$ & $12 \mathrm{~V}$ \\
Switching Frequency & $f_{s}$ & $500 \mathrm{kHz}$ \\
Output Current & $I_{o}$ & $125 \mathrm{~A}$ \\
Output Power & $p_{o}$ & $1.5 \mathrm{~kW}$ \\
Flying Capacitor & $C_{f l y}$ & $12 \mu \mathrm{F}$ \\
Middle Capacitor & $C_{\text {mid }}$ & $100 \mu \mathrm{F}$ \\
Output Capacitor & $C_{\text {out }}$ & $100 \mu \mathrm{F}$ \\
Resonant Capacitor & $C_{r}$ & $1 \mathrm{nF}$ \\
Resonant Inductor & $L_{r}$ & $10 \mathrm{nH}$ \\
Output Inductor & $L$ & $22 \mathrm{nH}$ \\
Resistor Load & $R_{\text {out }}$ & $96 \mathrm{~m} \Omega$ \\
Deadtime & $t_{d}$ & $10 \mathrm{~ns}$ \\
\hline
\end{tabular}

For four phases, each phase's inductor current will be shifted by a $90^{\circ}$ phase angle. Interleaving four currents will reduce output ripple as larger ripples get canceled as Fig. 17 illustrates. Peak mode current control as mentioned earlier maintains a balanced current load of $31.2 \mathrm{~A}_{\mathrm{RMS}}$ across the four phases. Early simulations show the output current ripple reducing from $200 \mathrm{~mA}$ to $593 \mu \mathrm{A}$, and the output voltage ripple from $15 \mathrm{mV}$ to $57 \mu \mathrm{V}$ due to interleaving function. While the results are not final, they do illustrate 
large gains to be benefited from interleaving. The transient response shows a stable change in voltage in Fig. 18 for a step-change in the output load. Fig. 19 highlights the flying capacitor's sinusoidal current, which suggests soft capacitor charging. As a result, switching losses are reduced in each phase. The efficiency increases when the phase of the MRSCBC converter increases which is shown in Fig. 20.

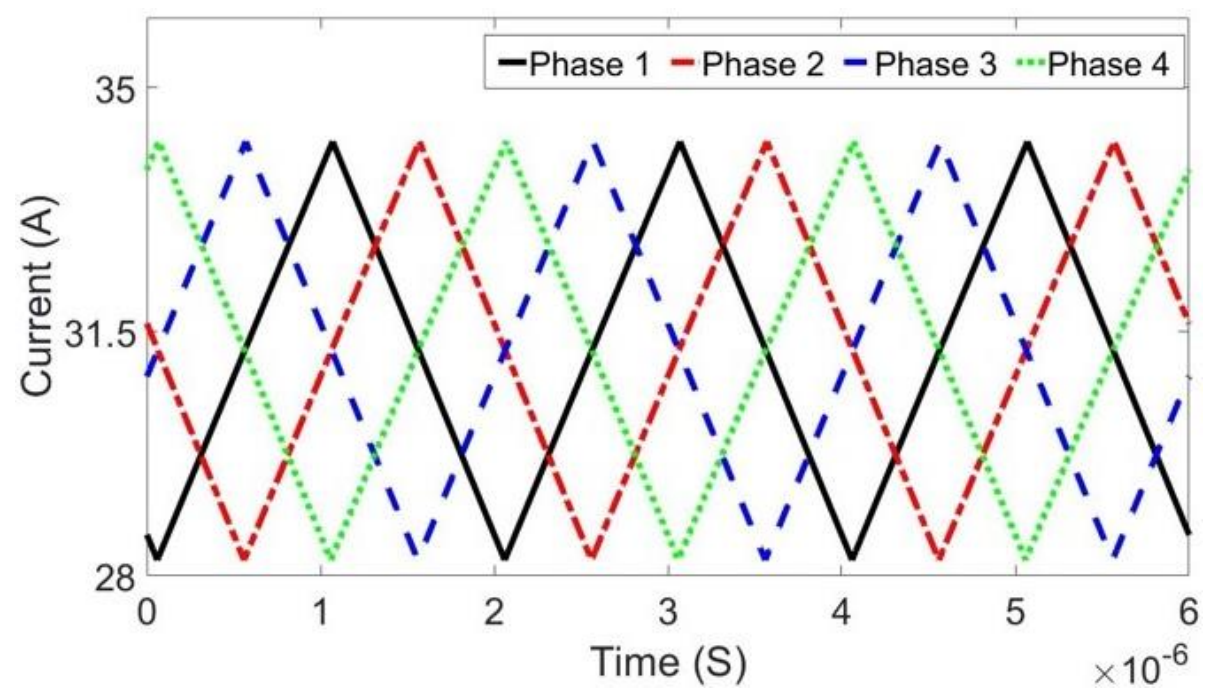

Fig. 17. MRSCBC four phases' interleaving currents.
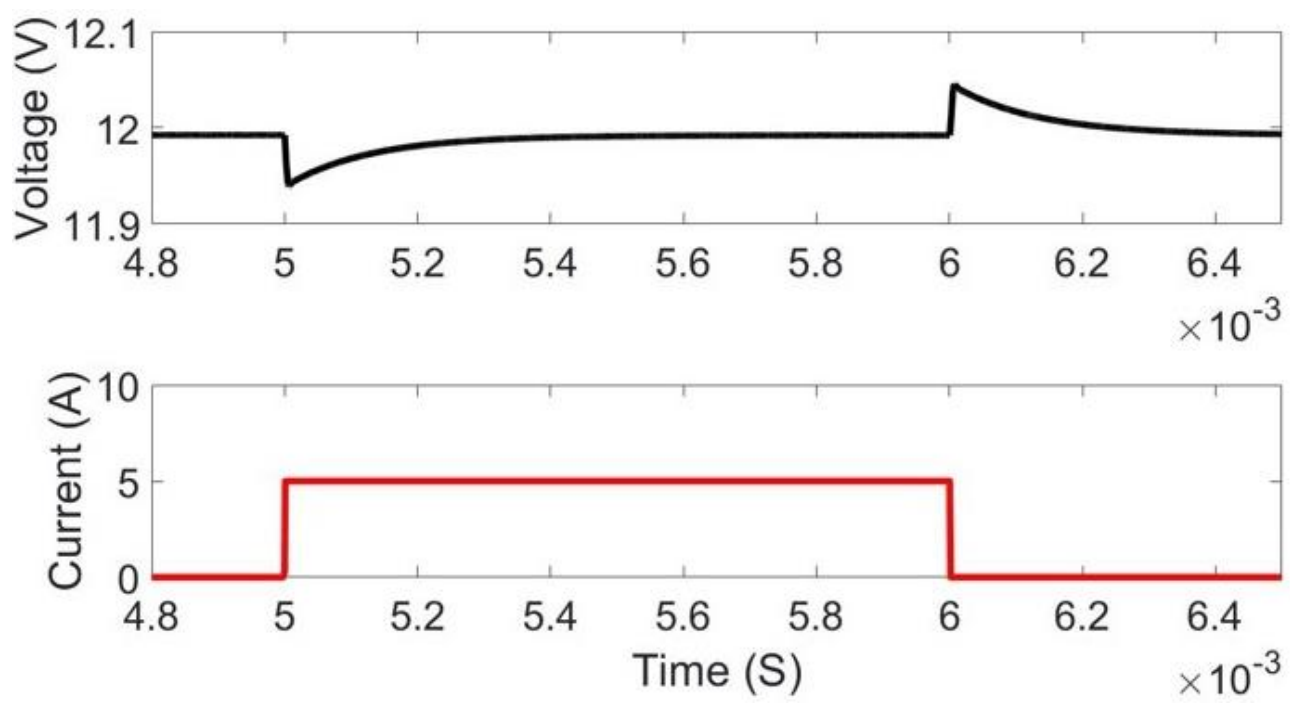

Fig. 18. MRSCBC transient response showing output voltage and output current. 


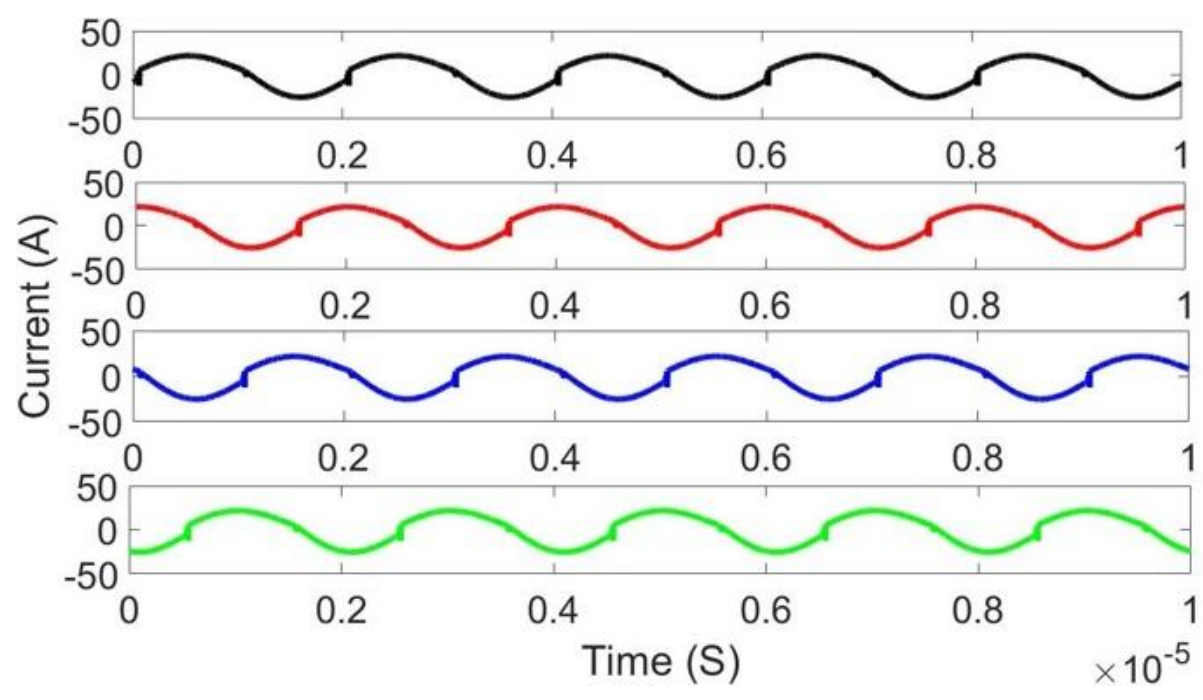

Fig. 19. MRSCBC flying capacitors' currents at full load of $1.5 \mathrm{~kW}$.

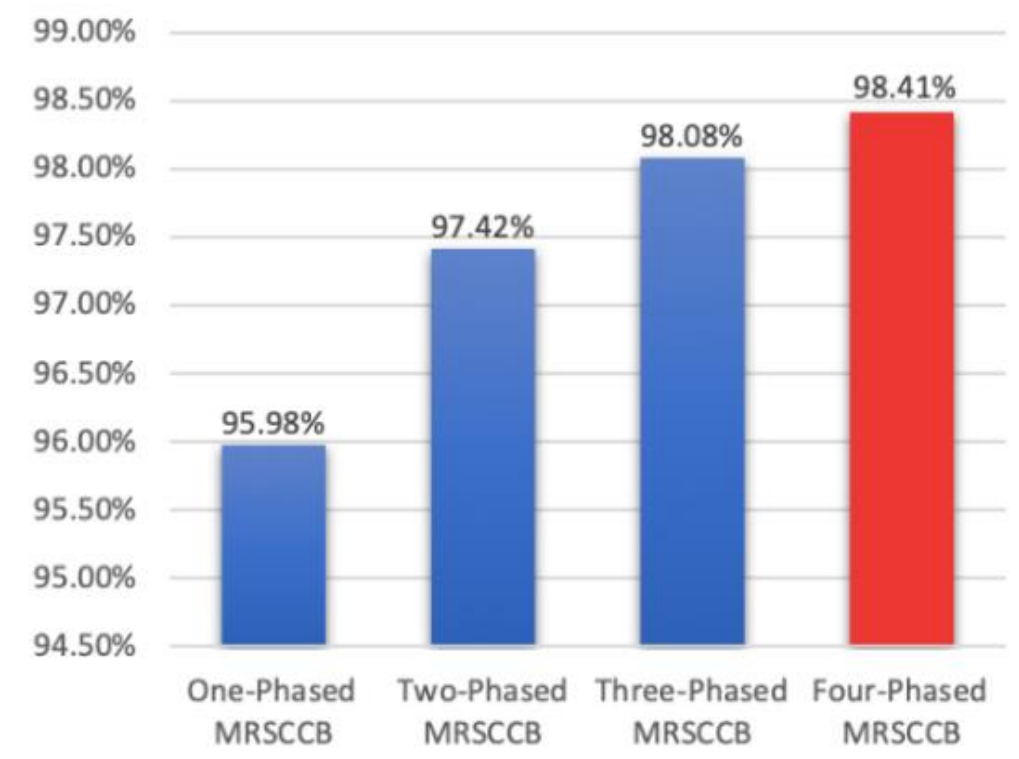

Fig. 20. Efficiency comparison of multi-phased MRSCBC at $1.5 \mathrm{~kW}$ output power.

\section{$3.3 \quad 300 \mathrm{kHz}$ Design}

It is worthwhile to investigate how the switching frequency affects the MRSCBC.

Switching losses and components values change with the switching frequency. The fourphase MRSCBC is recreated in Cadence Capture with 300kHz. Fig. 21 highlights experimental results that study immunity towards components variation. When the fly 
capacitor current is higher, then the capacitor charging, and resonant operation of the power circuit is less ideal. Compared to the RSCC, the MRSCC has high immunity towards the flying capacitor's variation when the switching frequency of the MRSCC is higher than its main resonant frequency at $\mathrm{k}=1.3$. By decreasing the switching frequency of MRSCC from $500 \mathrm{kHz}$ to $300 \mathrm{kHz}$, the RMS current of the flying capacitor reduces significantly at $\mathrm{k}=1.3$. Therefore, by selecting $\mathrm{k}$ to be around 1.3 , the MRSCC shows the immunity towards $\pm 20 \%$ flying capacitor's variation and better efficiency. Fig. 22 compares the efficiency improvement between $300 \mathrm{kHz}$ and $500 \mathrm{kHz}$. The startup voltage and interleaved current profiles of the built four-phase MRSCBC converter are shown in Fig. 23. For fast PCB parasitic analysis, a single-phase MRSCBC is created in Cadence Capture. Fig. 24 shows the steady-state output voltage profile of the converter.

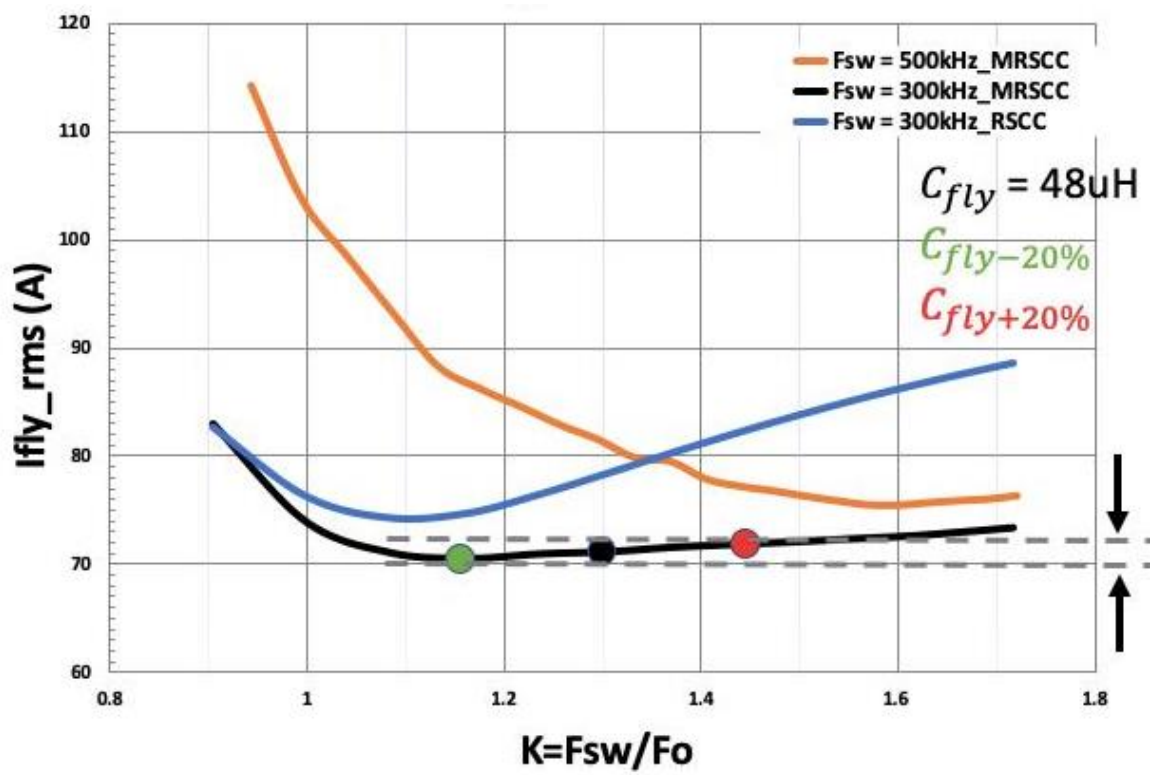

Fig. 21. Fly capacitor current change with respect to resonant and switching frequency mismatch. 


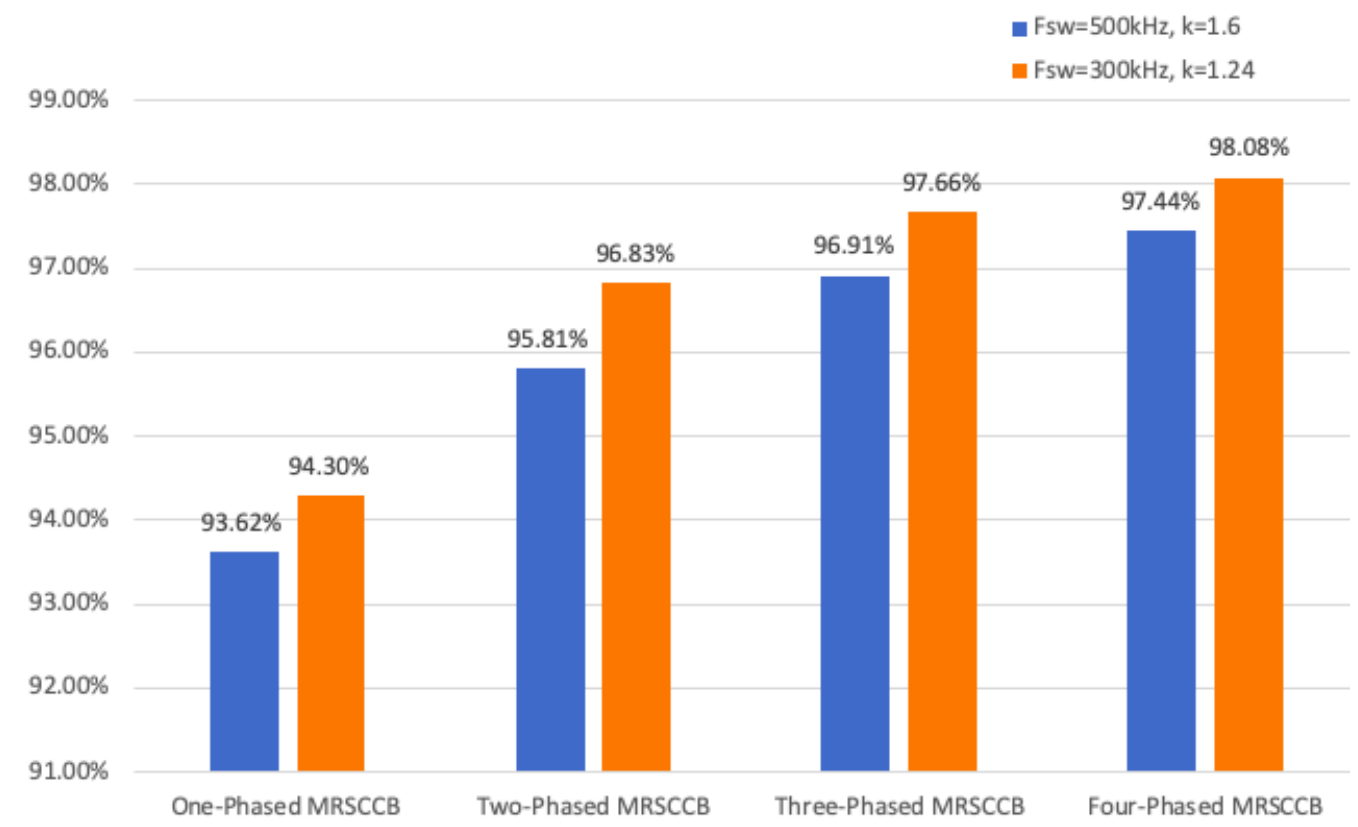

Fig. 22. Efficiency comparison of $300 \mathrm{kHz}$ and $500 \mathrm{kHz}$ design.

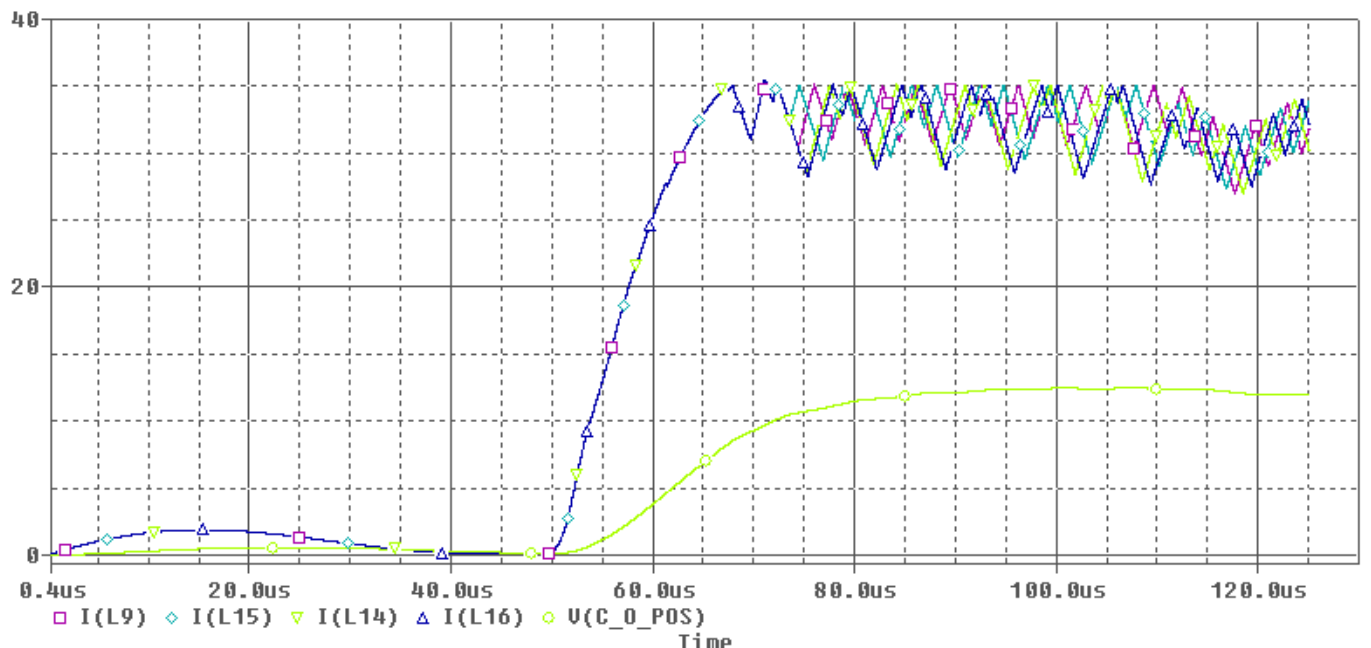

Fig. 23. Output voltage and inductor interleaved current during startup; (Y-axis shared between current and voltage signals). 


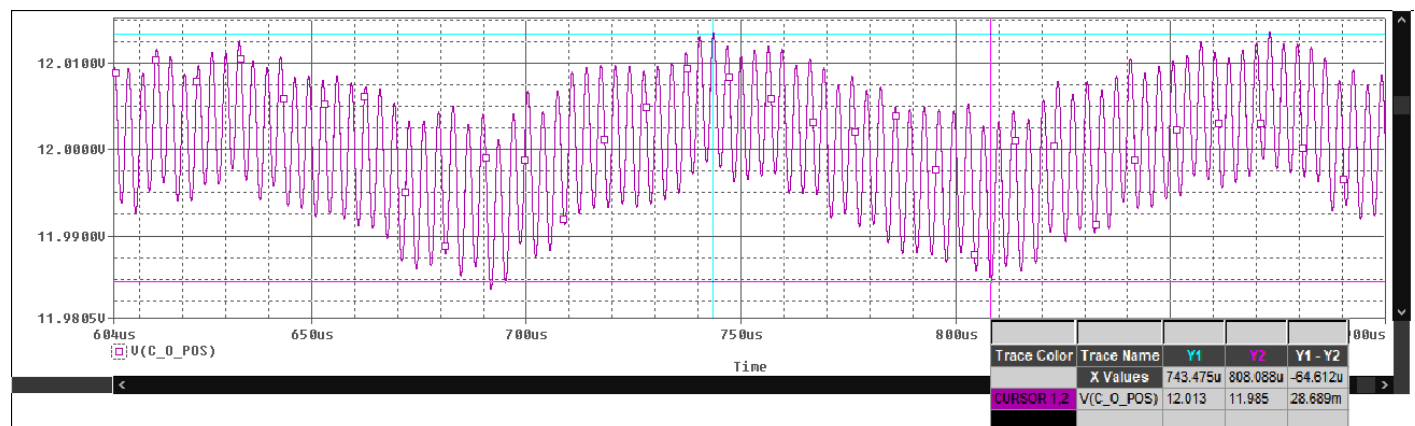

Fig. 24. Output voltage of designed MRSCBC. 


\section{SPICE AND PHYSICAL DESIGN}

The full design process of the proposed converter, shown in Fig. 25, starts with behavioral simulation design in SIMPLIS and moves to SPICE simulations in Cadence Capture. An initial PCB design is then created in OrCAD PCB Editor. Ansys Q3D imports the design and exports a PSpice model of the self and mutual parasitic elements in each net. The model is fed back into Cadence Capture to study the performance of the converter with the simulated parasitic elements.

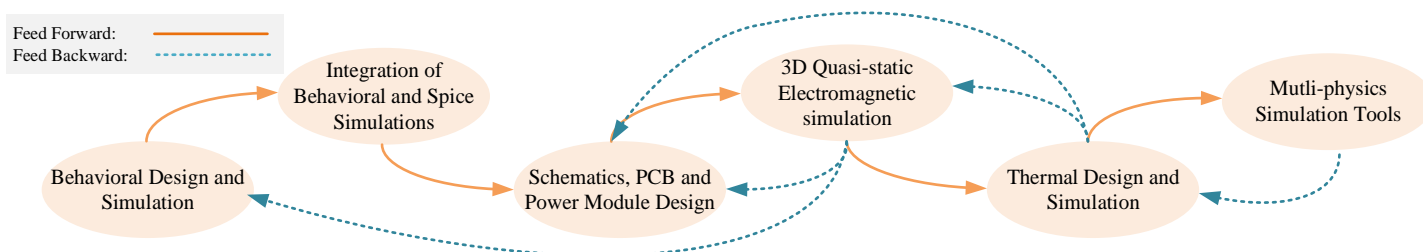

Fig. 25. Workflow diagram of the technical design approach used in this paper.

Texas Instrument's LM5141 synchronous buck controller featuring peak current mode control provides feedback closed-loop control signals to two UCC21520 isolated gate drivers per phase. Featuring a buck converter on the output of the multi-resonant switched capacitive converters allows the use of traditional synchronous buck controllers. Traditional control ICs simplify the design of the feedback control and allow for flexibility in choosing controllers as the synchronous buck controller with peak current mode control is common. The isolated gate drivers help reduce switching losses while each drives two gates.

OrCAD PCB editor is used to create a single-phase PCB design. The first design performed does not have to be final and contains all the thermal considerations. The initial PCB design is for parasitic analysis and as a result, the design is chosen such that it is focused on a realistic layout for the converter. To start the design an 8-layer board is 
chosen to provide flexibility in routing and EMI control with multiple ground planes. Fig. 26 shows the layer cross-section of the board with 4oz copper in each layer. Two ground planes on layers 2 and 7 ensure that any internal high-speed signal routing is shielded from EMI.

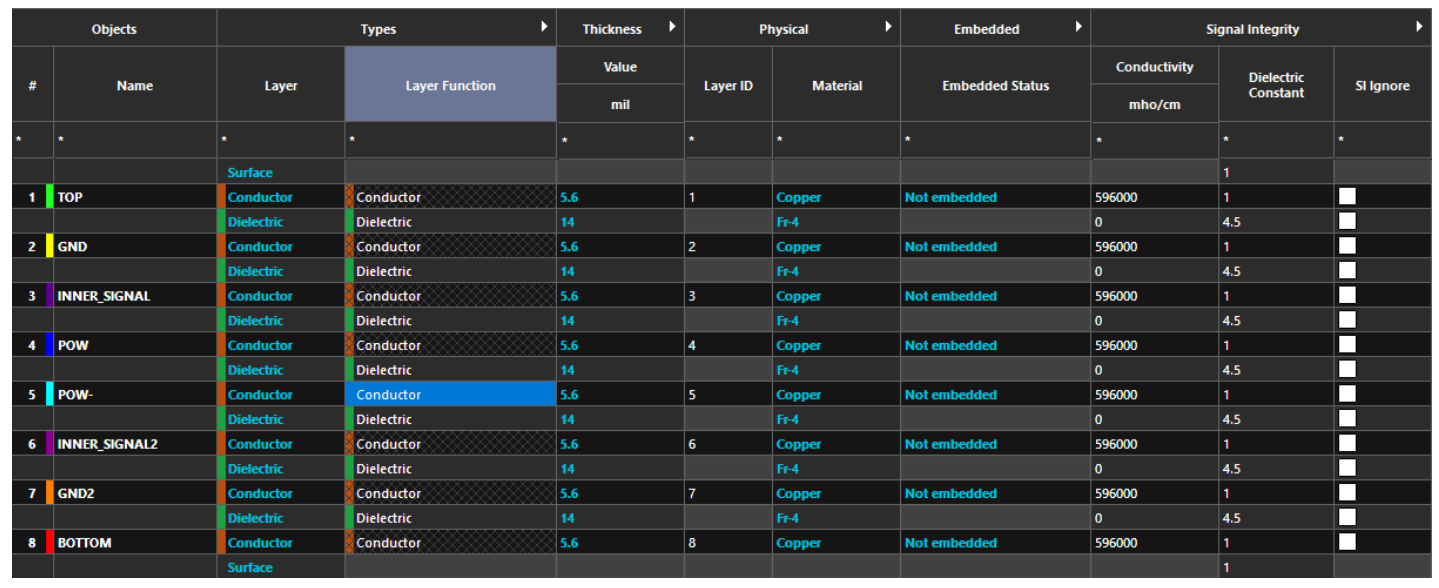

Fig. 26. Eight-layer cross section.

The first traces routed shown in green in Fig. 27 are the power traces as they are the least flexible to reroute and require the largest footprint. The remaining elements such as controllers, gate drivers, and voltage regulators are centered around the power circuit with their footprints catering to the need of the power circuit. The controller LM5141-Q1 is highlighted with a blue square and placed around the output and benefits from short trace length for feedback signals such as voltage and current sensing. The gate drivers highlighted with an orange square are placed physically close to the mosfets. The designed PCB imported into ANSYS Electronic Desktop is shown in Fig. 28. 


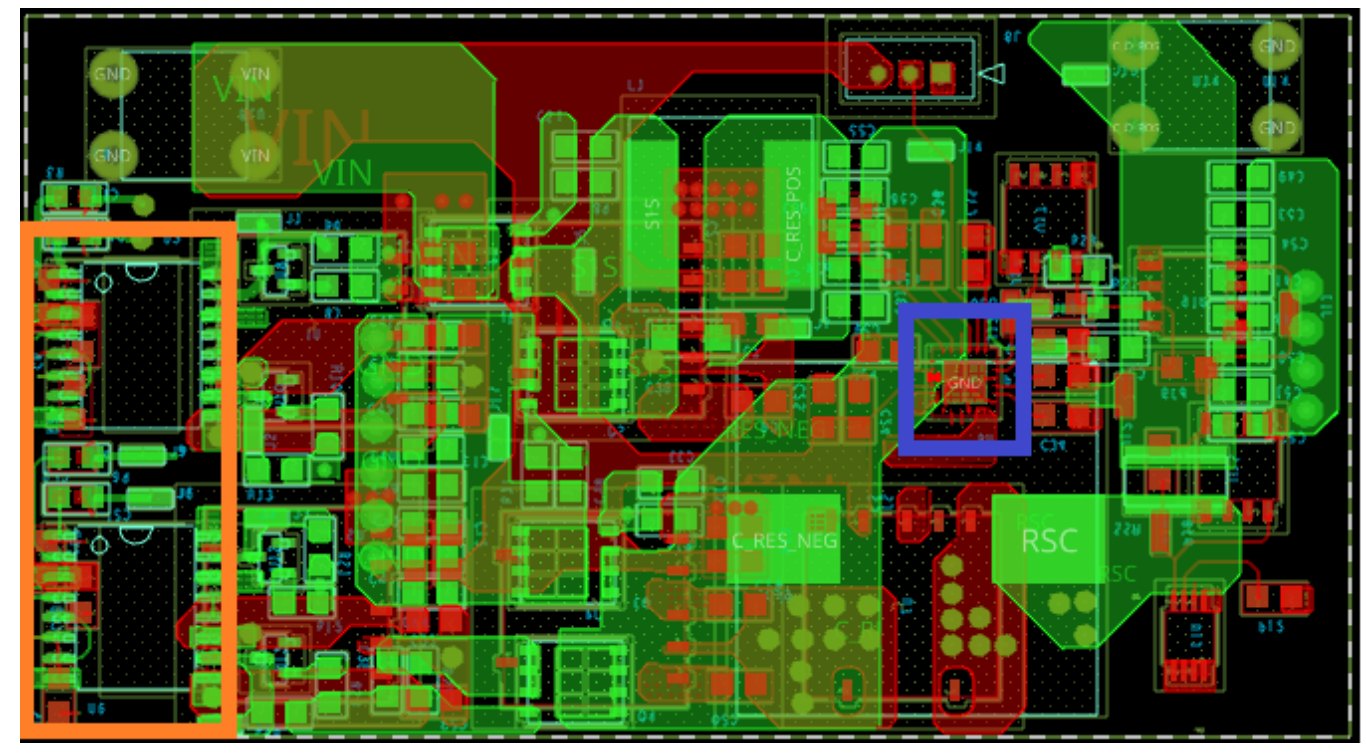

Fig. 27. First and final layer of the initial design highlighting component placement.

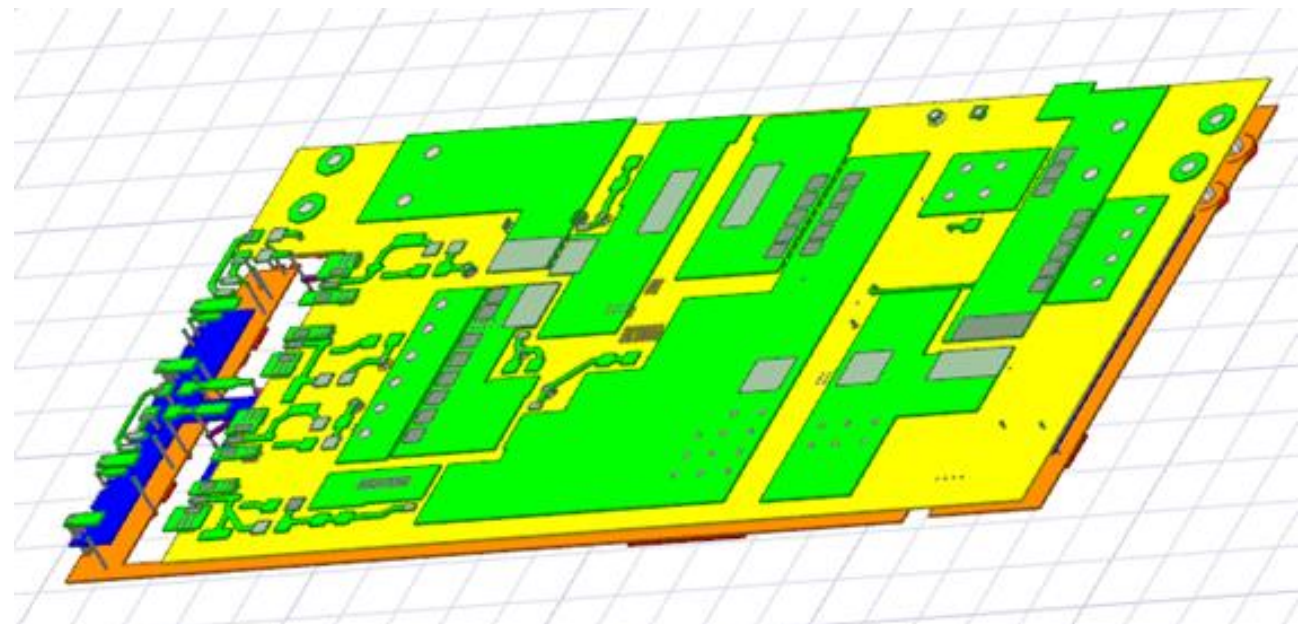

Fig. 28. PCB design in Q3D. 


\section{SIMULATION AND RESULT}

Q3D extracts a model for the self and mutual parasitic capacitance, inductance, and resistance and exports it as a PSpice file. The PCB model is imported into Ansys Q3D extractor which provides the values of the parasitic components at the switching frequency, $300 \mathrm{kHz}$ in this case. The self and mutual inductance and capacitance matrix are then imported into Cadence Capture as a square model. Fig. 29 displays the parasitic models connected to the circuit in Cadence Capture. Analysis of the performance of the converter with a parasitic model finds that the inductance is the most sensitive variable in design. Acceptable maximum inductance values range from $\mathrm{L} \times 10^{-11}$ to $\mathrm{L} \times 10^{-12}$. Higher inductance values in the $\mathrm{nH}$ range in the control and gate drive traces produce voltage spikes during rising and falling edges high enough to block the MRSCBC from starting or reaching $12 \mathrm{~V}$ output. Fig. 30 shows the startup response with original and reduced inductance values. The parasitic model highlights the importance of reducing the inductance in the control and gate drive traces in the PCB design. The multi-resonant power converter circuit, however, is tolerant to the forementioned inductance values.
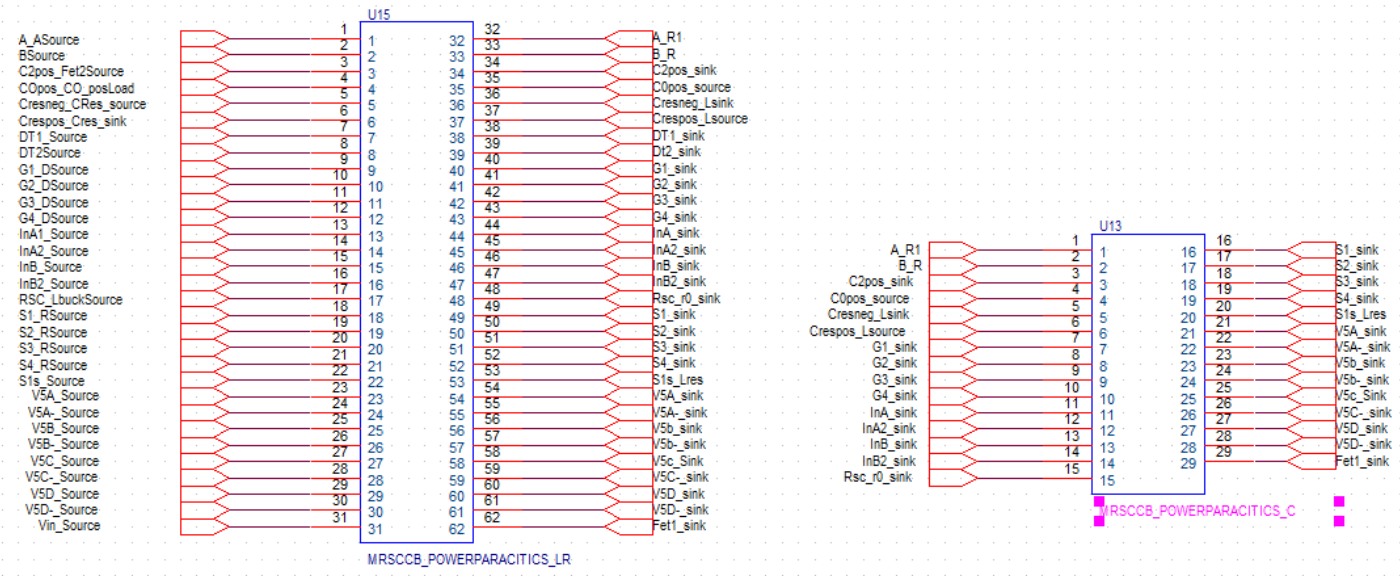

Fig. 29. Spice model of the parasitic elements in the designed PCB. 

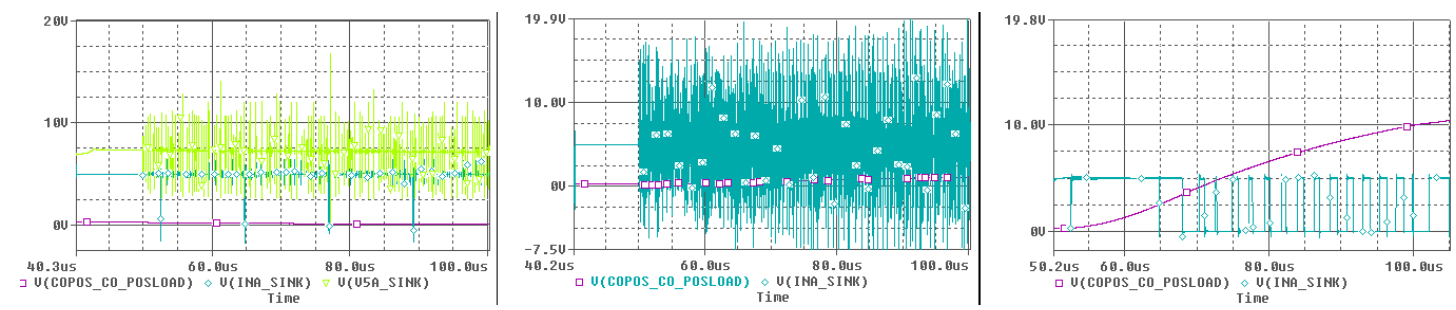

Fig. 30. Left to right: 1 . circuit failure to start with high parasitic inductance; 2 . circuit startup with lowered inductance in gate drive traces. 3. circuit Startup with lowered inductance in control and gate drive traces. 


\section{PCB REDESIGN AND EMI}

\subsection{PCB Redesign}

The information obtained from the Q3D analysis supports the need for a new PCB design. The original design aimed to provide feedback on the circuit's operation with parasitic elements. The redesign initially would focus on reducing the inductances of the traces between the gate driver and the switches. Due to the presence of many capacitors and inductors next to the switches in the MRSCBC, it is difficult to route the gate drive traces without utilizing vias. As a result, the gate drivers are moved underneath the Mosfets to reduce the length of the traces as possible. Fig. 31 compares the two trace paths.
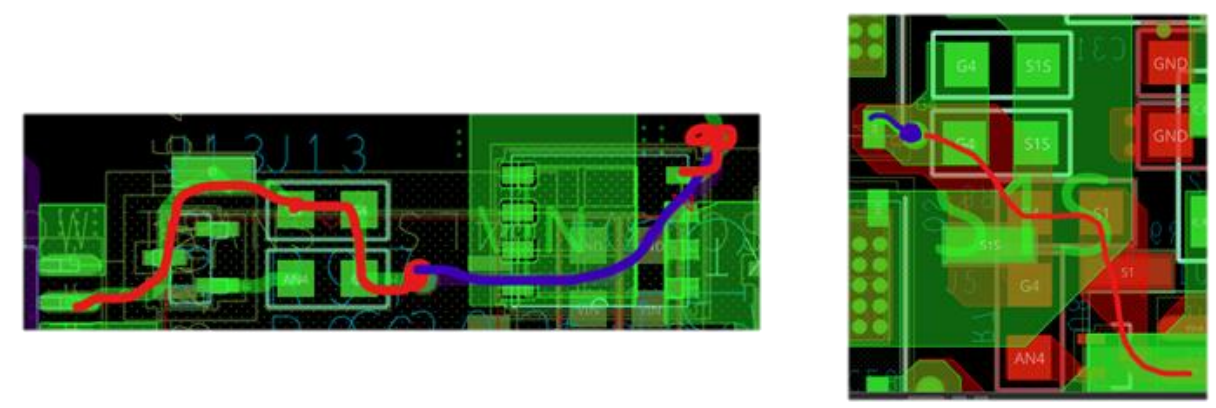

Fig. 31. Routing comparison of gate driver output with the old design on the left and new design on the right.

The redesign also focuses on other elements such as maximizing power density and including some heat management. Thermal vias are used underneath the switching mosfets as shown in Fig. 32. The inductor choice is changed to a shorter inductor, and the design overall is brought closer together as depicted in Fig. 33. Capacitors with 1206 size used in the place of the power capacitors $\mathrm{C}_{\text {fly }}$ and $\mathrm{C}_{2}$ to help with heat dissipation of the current as shown in Fig. 34. The number of layers is reduced from 8 layers to 6 to help 
reduce current loop sizes. A chassis ground added is shown in Fig. 35 and Fig. 36 highlights the overall compact improvements of the design. Analysis of the parasitic inductances is performed again the results are displayed in Fig. 37. A bill of material is prepared and shown in Table 4.

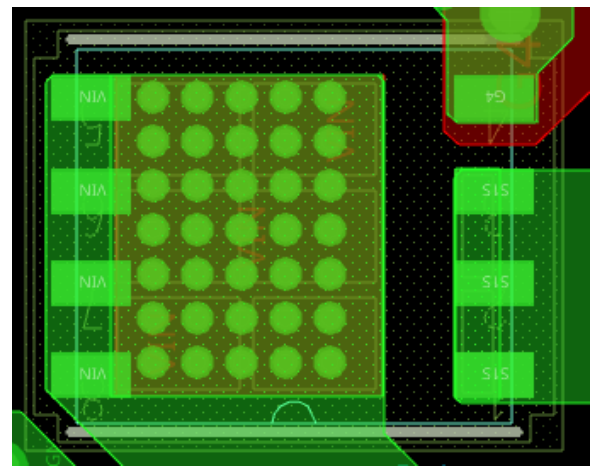

Fig. 32. Thermal vias underneath the mosfets.
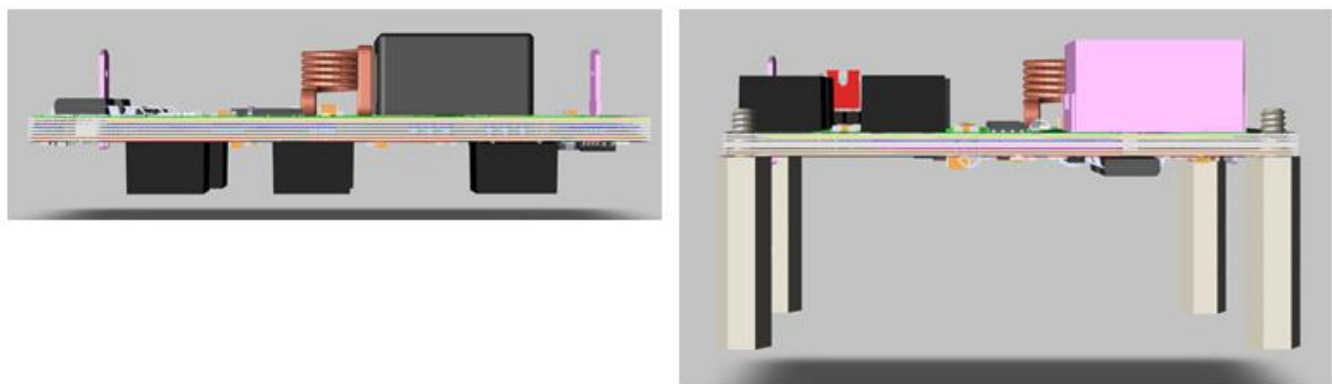

Fig. 33. Height comparison of original design (left) and redesign (right).
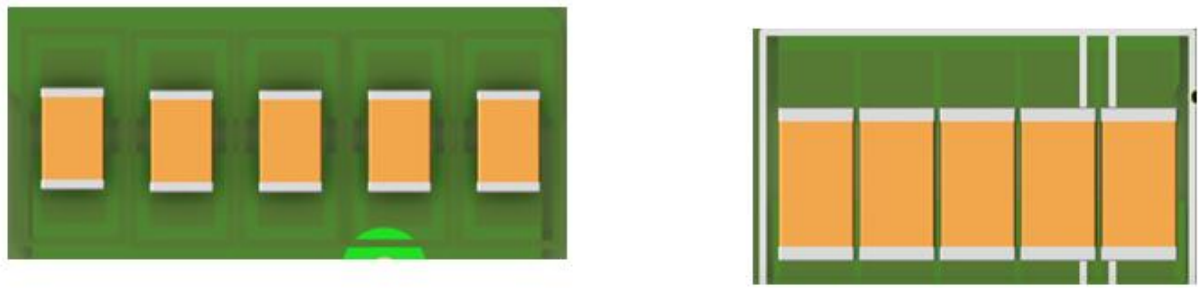

Fig. 34. Power capacitor size comparison between original (left) and redesign (right). 


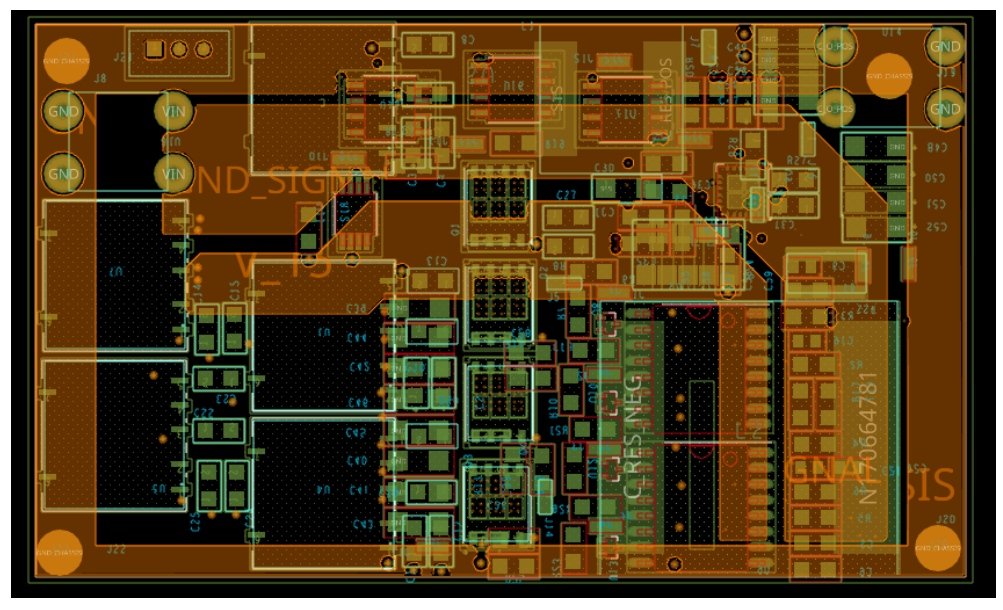

Fig. 35. Routing of chassis ground.
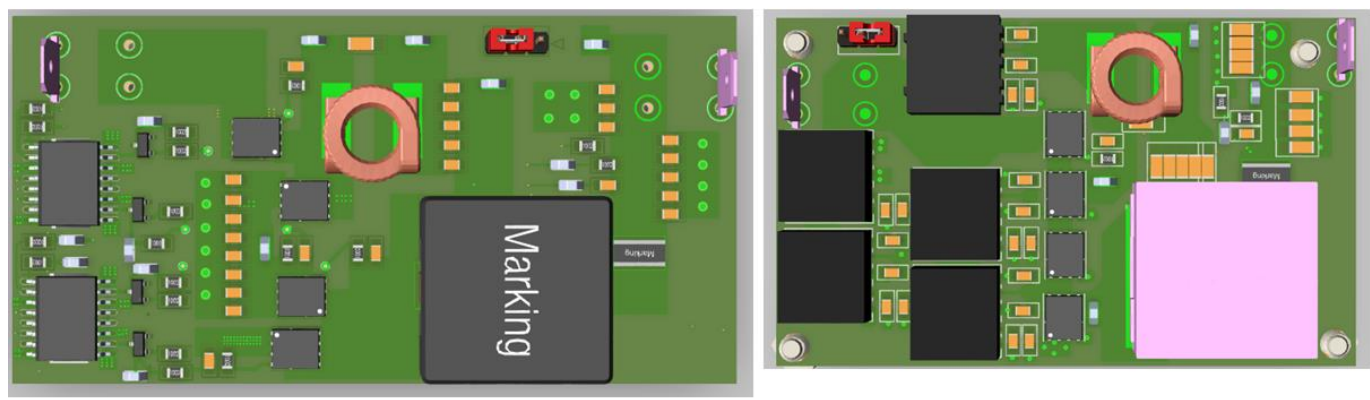

Fig. 36. Overall design comparison highlighting compactness between original (left) and redesign (right).

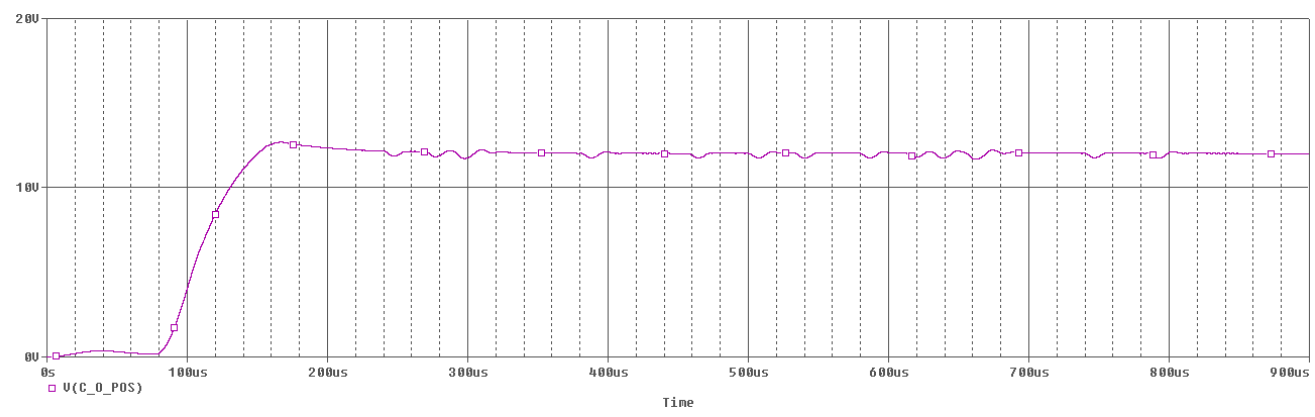

Fig. 37. Output of PSpice simulations with redesign parasitics. 
Table 4. Bill of Materials.

\begin{tabular}{|c|c|c|c|c|}
\hline $\begin{array}{l}\text { Item } \\
\# \\
\end{array}$ & Value & Manufacture & Manufacture \# & $\begin{array}{l}\text { Qty } \\
\text { 4phs }\end{array}$ \\
\hline 1 & $10 n$ & Würth Elektronik & 885012207122 & 36 \\
\hline 2 & $0.1 \mathrm{u}$ & Würth Elektronik & 885012207128 & 32 \\
\hline 3 & $10 \mathrm{p}$ & Würth Elektronik & 885012006073 & 16 \\
\hline 4 & 1n & Würth Elektronik & 885012207116 & 56 \\
\hline 5 & $46 n$ & KEMET & $\begin{array}{l}\text { C0805C473J1RAC } \\
7800\end{array}$ & 4 \\
\hline 6 & $5 p$ & Würth Elektronik & 885012007101 & 4 \\
\hline 7 & $5 n$ & Würth Elektronik & 885012007092 & 4 \\
\hline 8 & $120 n$ & KEMET & $\begin{array}{l}\text { C0805C124K1RA } \\
\text { CTU }\end{array}$ & 4 \\
\hline 9 & $0.33 \mathrm{u}$ & Würth Elektronik & 885012207101 & 4 \\
\hline 10 & $\begin{array}{l}4.7 \mathrm{uF}(2 \times 2.2 \mathrm{uF} \\
\text { stacked })\end{array}$ & $\begin{array}{l}\text { Samsung Electro- } \\
\text { Mechanics }\end{array}$ & $\begin{array}{l}\text { CL31B225KCHSN } \\
\text { NE }\end{array}$ & 80 \\
\hline 11 & $10 \mathrm{uF}$ & Würth Elektronik & 885012208041 & 40 \\
\hline 12 & Pin & Keystone Electronics & 5015 & 60 \\
\hline 13 & CON_532530370 & Molex & 532530370 & 4 \\
\hline 14 & $22 \mathrm{nH}$ & Würth Elektronik & 7449152022 & 4 \\
\hline 15 & $4.7 \mathrm{u}$ & Pulse Electronics Power & PA4349.472ANLT & 4 \\
\hline 16 & BSC032N04LS & Infineon Technologies & $\begin{array}{l}\text { BSC032N04LSAT } \\
\text { MA1 }\end{array}$ & 16 \\
\hline 17 & 50 & Vishay Dale & $\begin{array}{l}\text { RCS080549R9FK } \\
\text { EA }\end{array}$ & 16 \\
\hline 18 & $10 \mathrm{k}$ & $\begin{array}{l}\text { Panasonic Electronic } \\
\text { Components }\end{array}$ & ERA-6AEB103V & 32 \\
\hline 19 & 8 & $\begin{array}{l}\text { Panasonic Electronic } \\
\text { Components }\end{array}$ & ERJ-6BQF1R0V & 4 \\
\hline
\end{tabular}




\begin{tabular}{|l|l|l|l|l|}
\hline 20 & $76 \mathrm{k}$ & $\begin{array}{l}\text { Panasonic Electronic } \\
\text { Components }\end{array}$ & ERJ-6ENF7682V & 4 \\
\hline 21 & $73.7674 \mathrm{k}$ & $\begin{array}{l}\text { Panasonic Electronic } \\
\text { Components }\end{array}$ & ERA-6AEB7322V & 4 \\
\hline 22 & 0 & Vishay Dale & $\begin{array}{l}\text { CRCW08050000Z } \\
\text { 0EBC }\end{array}$ & 12 \\
\hline 23 & 0 & Wurth Electronics & 581070763001 & 4 \\
\hline 24 & $9.1 \mathrm{~K}$ & $\begin{array}{l}\text { Panasonic Electronic } \\
\text { Components }\end{array}$ & ERA-6ARB912V & 4 \\
\hline 25 & $94.1 \mathrm{k}$ & $\begin{array}{l}\text { TE Connectivity Passive } \\
\text { Product }\end{array}$ & $\begin{array}{l}\text { RQ73C2A93K1BT } \\
\text { D }\end{array}$ & 4 \\
\hline 26 & TRS2-4823 & Traco Power & TRS 2-4823 & 16 \\
\hline 27 & $\begin{array}{l}\text { UCC21520DW_T } \\
\text { RANS }\end{array}$ & Texas Instruments & UCC21520DW & 8 \\
\hline 28 & TRS2-4813 & Traco Power & TRS 2-4813 & 4 \\
\hline 29 & BAT54 & ON Semiconductor & BAT54 & 16 \\
\hline 30 & LM5141-Q1RGE & Texas Instruments & LM5141-Q1 & 4 \\
\hline 31 & ds1090u-16 & Maxim Integrated & DS1090U-16+ & 4 \\
\hline 32 & 2 Tab & $\begin{array}{l}\text { TE Connectivity AMP } \\
\text { Connectors }\end{array}$ & $63986-1$ & 16 \\
\hline 33 & DS1100Z-500 & Maxim Integrated & DS1100Z-500+ & 8 \\
\hline 34 & DS1100Z-40 & Maxim Integrated & DS1100Z-40+ & 4 \\
\hline 35 & Test Point & Keystone Electronics & 4820 & 100 \\
\hline
\end{tabular}

\subsection{EMI Analysis}

PSIM is used to run EMI simulation on conducted noise. The MRSCBC is recreated in PSIM with the parasitic values found during ANSYS Q3D Simulations. Fig. 38 shows the MRSCBC with parasitic inductances in the power traces. An EMI line filter with part number 810911010 is chosen from Würth Elektronik and is shown in Fig. 38. The line 
filter is shown in Fig. 39 for reference. The EMI of the circuit is shown in Fig. 40 passing CISPR 22 standards.

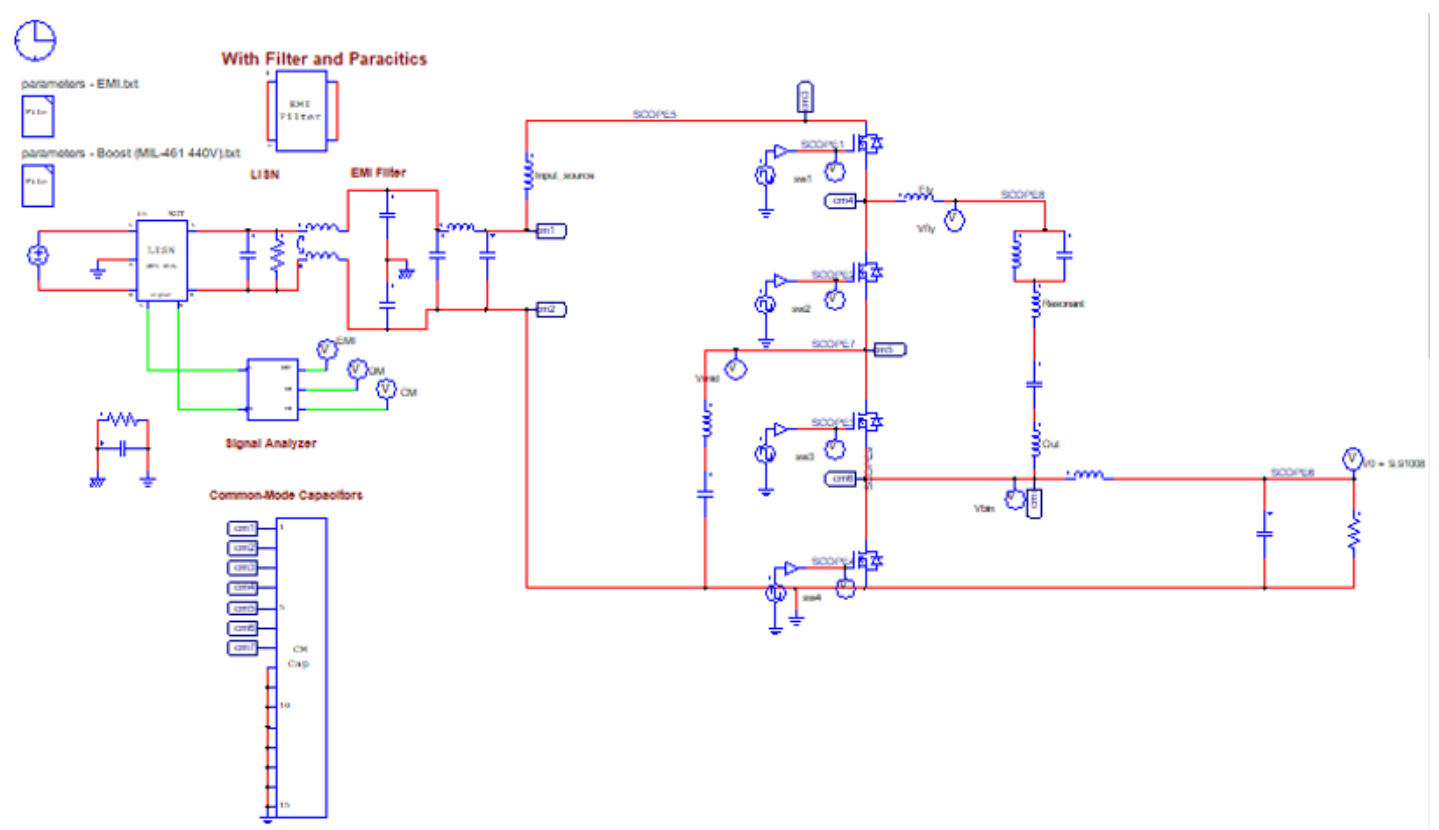

Fig. 38. PSIM model with parasitic inductances in the power traces.

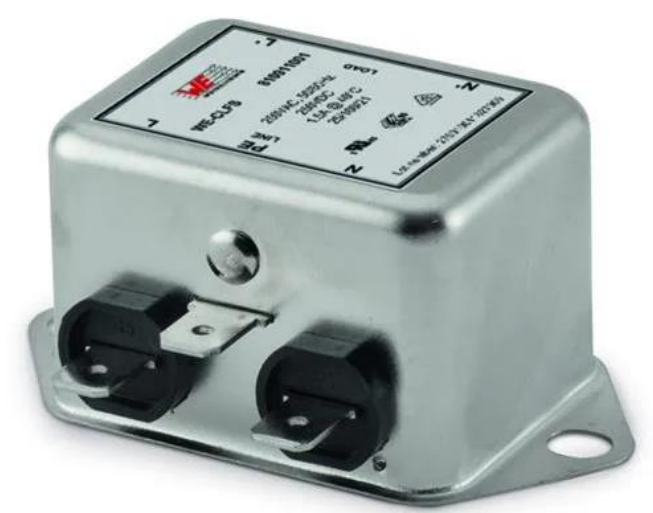

Fig. 39. 810911010 Line filter from Würth Elektronik. 


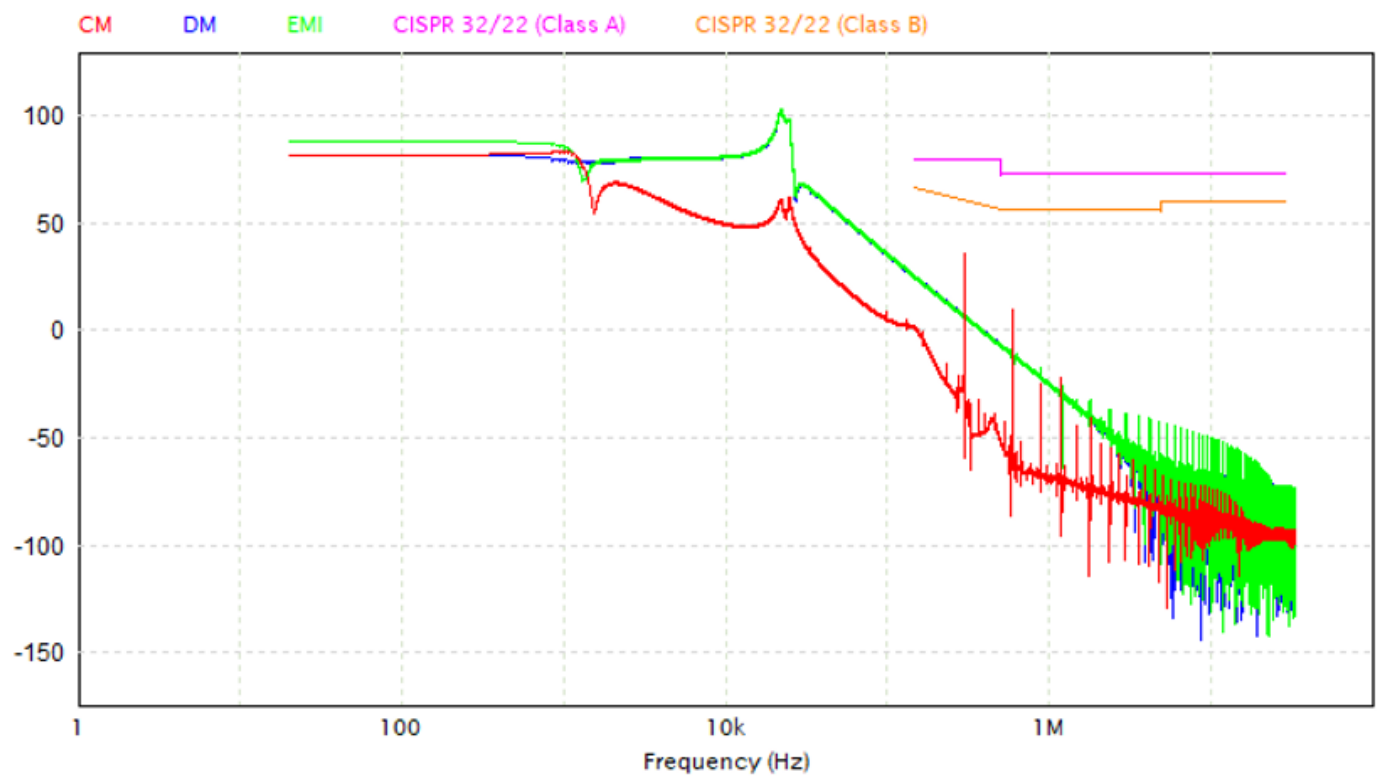

Fig. 40. EMI results of simulation shown passing CISPR 22 standards. 


\section{CONCLUSION}

Analysis through ANSYS Electronic Desktop allows for the simulation of the operation of the design close to experimental data and provides feedback on improvements before the design is completed. An acceptable inductance range value in the gate drive and switching traces are presented for the operation of the MRSCBC. Future work constitutes an experimental prototype of the proposed converter to validate the system's effectiveness and highly efficient characteristics.

Gallium nitride's application is worth considering due to its rising popularity. Designing short gate drive traces is challenging as shown in previous attempts to design a PCB for the MRSCBC. The presence of two inductors and two arrays of power capacitors around the switches cause a blockage around the switched for routing nonpower signals. Gallium nitride technology's high switching speed cause higher susceptibility to parasitic inductances in the traces than silicon mosfets. As a result, gallium nitride application for the MRSCBC is discouraged until better routing techniques are available for the MRSCBC which ensures tight gate drive loops. 


\section{Literature Cited}

[1] Texas Instruments, "Buck regulator architectures - multi-phase buck regulators," 2502 2013. [Online]. Available: https://training.ti.com/buck-regulatorarchitectures-multi-phase-buck-regulators?cu=5177. [Accessed 1506 2021].

[2] T. N. M. H. T. Z. Seiya Abe, "Stability Comparison of Three Control Schemes," in 2005 International Conference on Power Electronics and Drives Systems, Kuala Lumpur, Malaysia, 2005.

[3] T. N. M. H. T. Z. Seiya Abe, "Stability Design Consideration for On-Board Distributed Power System Consisting of," in 2006 37th IEEE Power Electronics Specialists Conference, Jeju, Korea (South), 2006.

[4] H. Huang, "Designing an LLC Resonant Half-Bridge Power Converter," Texas Instruments Incorporated, Dallas, Texas, 2010.

[5] S. Abdel-Rahman, "Infineon," 09 2012. [Online]. Available: https://www.infineon.com/dgdl/Application_Note_Resonant+LLC+Converter+O peration+and+Design_Infineon.pdf?fileId=db3a30433a047ba0013a4a60e3be64a1 . [Accessed 1406 2021].

[6] EPC, "Efficient Power Conversion," Efficient Power Conversion, [Online]. Available: https://epc-co.com/epc/GalliumNitride/WhatisGaN.aspx. [Accessed 15 06 2021].

[7] Z. C. R. W. F. L. D. B. P. M. Milisav Danilovic, "Evaluation of the Switching Characteristics of a Gallium-Nitride Transistor," 2011 IEEE Energy Conversion Congress and Exposition, vol. 10.1109, no. 2011.6064128., pp. pp. 2681-2688, 2011.

[8] Power Integrations, "PowiGaN Technology," Power Integrations, [Online]. Available: https://www.power.com/company/our-innovations/powigantechnology. [Accessed 1506 2021].

[9] On Semiconductor, "On Semiconductor," 03 2020. [Online]. Available: https://www.onsemi.com/pub/Collateral/TND6299-D.PDF. [Accessed 1506 2021].

[10] EPC Corporation, "How to GaN 01 - Material Comparisons," EPC Corportation, 2903 2020. [Online]. Available: How to GaN 01 - Material Comparisons. [Accessed 1506 2021]. 
[11] M. H. Ahmed, F. C. Lee and Q. Li, "LLC Converter with Integrated Magnetics Application for 48V Rack Architecture in Future Data Centers," in 2019 IEEE Conference on Power Electronics and Renewable Energy (CPERE), Aswan City, Egypt, 2019.

[12] L. Duan, D. Zhan and J. Hohnerlein, "Optimizing Cloud Data Center Energy Efficiency via Dynamic Prediction of CPU Idle Intervals," in 2015 IEEE 8th International Conference on Cloud Computing, New York, NY, 2015.

[13] S. jiang and X. Li, "Google 48V Power Architecture, Plenary," in IEEE Applied Power Electronics Conference and Exposition - APEC. Keynotes presentation, 2017.

[14] X. Lyu, Y. Li, Z. Ni, J. Johnson, D. Cao, C. Nan and S. Jiang, "Composite Modular Power Delivery Architecture for Next-Gen 48V Data Center Applications," in 018 1st Workshop on Wide Bandgap Power Devices and Applications in Asia (WiPDA Asia), Xi'an, China, 2018.

[15] Vicor Corporation, "NBMTM Bus Converter NBM2317S60E1560T0R," Vicor Corporation, Andover, 2019.

[16] M. Xu, J. Sun and F. Lee, "Voltage divider and its application in the two-stage power architecture," in Twenty-First Annual IEEE Applied Power Electronics Conference and Exposition, 2006. APEC '06, Dallas, TX, 2006.

[17] O. Jong, Q. Li and F. C. Lee, "Resonant Switched-Capacitor Converter with Multi-Resonant Frequencies," in 2019 IEEE Applied Power Electronics Conference and Exposition (APEC), Anaheim, CA, USA, 2019.

[18] S.-C. Tan, M. Nur, S. Kiratipongvoot, S. B. Y. Lai, C. K. Tse and A. Loinovici, "Switched-capacitor converter configuration with low EMI emission obtained by interleaving and its large-signal modeling," in 2009 IEEE International Symposium on Circuits and Systems (ISCAS), Taipei, 2009. 